\title{
Zur Gletscher-, Vegetations- und Klimageschichte der Schweiz seit der Späteiszeit
}

\author{
Abstract (Furrer et al.)
}

A statistical analysis of published and compilated snowline data for the late-glacial stades of Gschnitz, Clavadel, Daun and Egesen is presented. The calculation of snowline and snowline-depression (compared to the extent of 1850) is based on the $2: 1$-equilibrium line method. The interpretation does not show significant differences in snowline-depression between the Lower Engadin (Eastern Alps) and the Mont Blanc area (Western Alps). The larger deviations from the averages can be explained by the glacier individuality (morphology, topography of the ice surfaces) and the rarely considered variations of the "constant" 2: 1-ration. Geographical patterns, which could imply changes in paleo-precipitation, cannot be found in the investigated area.

The Quaternary vegetation history provides evidence for climatic changes and timberline fluctuations which took place during the Late-Glacial and Holocene and also provides a framework for biostratigraphical results. During the Oldest Dryas a heliophile Artemisia-Chenopodiceae-Helianthemum-Thalictrum-Ephedra-Juniperus-Betula nana pioneer vegetation covered the icefree areas in Switzerland. The oldest pollen spectra found in clay gyttja sediments are dated between 13,000 and 14,000 y BP by the radiocarbon method. The development of the Swiss Central Alpine wood belt since the Late-Glacial is shown in Fig. 11.

Postglacial alterations of the geomorphological activity in the Alps can be reconstructed by radiocarbon dating of fossil soils found in moraines, earth-flows and talus deposits. The results show that the geomorphological activity was very slow up to 4500 y BP; but the second part of the postglacial period was marked by often changing phases of activity and stability.

Differing qualities of the evidence relating to glacial history and the absence of glacier advances within several periods of the Holocene make it impossible to reconstruct a complete curve of the glacier movements. With the aid of a graphical diagram which includes both evidence on glacier fluctuations and dendroclimatological analysis, it will be shown that the Alpine glaciers probably oscillated inside different "levels".

\section{Einleitung \\ (G. Furrer)}

Seit bald 20 Jahren beschäftigt sich die Arbeitsgruppe um G. Furrer, Abteilung Physische Geographie am Geographischen Institut der Universität Zürich-Irchel, mit der rund 18000 Jahre umfassenden spät- und nacheiszeitlichen Geschichte der Alpengletscher. Die damit in Zusammenhang stehenden vegetationsgeschichtlichen Aspekte bilden seit über zehn Jahren einen zweiten Untersuchungsschwerpunkt.

Nebst den verschiedenen geomorphologischen und pollenanalytischen Methoden wird am gleichnamigen Institut mit Erfolg die Jahrringanalyse angewendet. Auch die Auswertung historischer Bildund Schriftquellen sowie alter meteorologischer Beobachtungsreihen bilden einen methodischen Schwerpunkt. Den nacheiszeitlichen Schwankungen der solifluidalen Aktivität in den Schweizer Alpen wird seit etwa 30 Jahren spezielle Beachtung geschenkt. Von nicht geringerer Bedeutung sind Bodenbildungsvorgänge, welche an Hand von fossilen und rezenten Böden in Moränen. Schutthalden, Schuttfächern, unter Solifluktionsdecken und in Zusammenhang mit Bergsturzmassen bezüglich der Paläogeographie und Paläoklimatologie intensiv studiert werden.

Die zunächst relativ datierten Vorgänge zur Landschaftsformung werden mittels des institutseigenen ${ }^{1+} \mathrm{C}$-Labors und mit Hilfe der Jahrringanalyse durch absolute Datierung in die chronologische Skala eingefügt. Das Hauptziel dieser vielfältigen Untersuchungen liegt in der Rekonstruktion der quartären Klimageschichte, besonders ihres jüngeren $\mathrm{Ab}$ schnittes. Als Zeiger von Klimaänderungen dienen uns Gletscherschwankungen, einschneidende Vegetations- und Holzzuwachsveränderungen sowie morphodynamische Ereignisse.

\section{Key words:}

Late-Glacial stages, snowline-depression, paleo-precipitation, Late-Glacial vegetation history, Oldest Dryas pioneer vegetation, Swiss Central wood belt, geomorphological activity in the Swiss Alps, fossil soils, Holocene Alpine glacier fluctuations, glacial history, dendroclimatology.
Gerhard Furrer, Prof., Dr.; Conradin Burga, PD Dr.; Hans-Peter Holzhauser, Dr.; Max Maisch, Dr.; Geographisches Institut der Universität Zürich-Irchel, Winterthurerstr. 190, 8057 Zürich, Martin Gamper, PD Dr., Wiesenstr. 32, 8700 Küsnacht. 
Die Arbeitsweise während den letzten 20 Jahren kann in drei Phasen eingeteilt werden:

Die erste Phase ist gekennzeichnet durch einzelne empirische Feldstudien, die zunächst untereinander eher geringe Berührungspunkte aufweisen. Als Beispiel hiezu seien die Arbeiten von G. FURRER (1954, $1955,1965,1968,1972)$, G. FURRER und P. FITZE (1970a und 1970b), P. ABT, F. BACHMANN, J. BÜHLER und G. FURRER (1971), G. FURRER, F. BACHMANN und P. FITZE (1971, G. FURRER und R. FREUND (1973), H. ELSASSER (1968) D. C. HARTMANN-BRENNER (1973), K. GRAF (1971), O. KELLER (1973), U. KÄSER (1980) und F. BEELER (1977) erwähnt.

In der zweiten Phase wurden die Feldarbeiten durch Anwendung weiterer Methoden ergänzt, wie Jahrringanalyse, Lichenometrie, Pollenanalyse und durch die Auswertung fossiler Böden erweitert. Mit diesen Arbeiten wurden vermehrt klimamorphologische Interpretationen der beschriebenen Formenbildungsprozesse angestrebt. Es sind dies u. a. die Arbeiten von M. GAMPER $(1981,1985)$, N. F. KAISER (1979), G. FURRER (1977), G. FURRER und F. BACHMANN (1972), G. FURRER, H. LEUZINGER Und K. AMMANN (1975), W. SCHNEEBELI (1976), F.RÖTHLISBERGER (1976), C. BURGA (1975, 1981), M. MAISCH (1981), J. SUTER (1981), F. RENNER (1982), H. P. HOLZHAUSER (1984), W. BIRCHER (1982), H. AESCHLIMANN (1983), R. VUAGNEUX (1983), A. E. VOEGELE (1984), R BLESS (1984), M. FRIES (1985), P. STALDER (1985), R. HIPP (1986) und W. WETTER (1987).

Erste räumliche und zeitliche Syntheseversuche zur spät- und nacheiszeitlichen Gletscher- und Klimageschichte kennzeichnen die dritte Phase, welche derzeit noch nicht abgeschlossen ist. Hierzu sind vor allem folgende Veröffentlichungen aus dem Geographischen Institut der Universität Zürich zu nennen: G. FURRER und J. SUTER (1979), C. BURGA (1979. 1985) G. FURRER,B. GAMPER und J. SUTER (1980). G. FURRER, H. HOLZHAUSER, M. MAISCH und J.SUTER (1982), M. MAISCH (1982), M. GAMPER und J. SU. TER (1982, H. HOLZHAUSER (1982), J.SUTER (1982), R. MÜLLER (1982) und P. FITZE (1982).

Der Forschungsbereich «Klimageschichte», mit G. Furrer als Vorsitzendem, als laufendes Projekt der Schweizerischen Kommission für Klima- und Atmosphärenforschung, zeigt die vermehrte Vernetzung der geomorphologischen Forschung mit an- dern Wissenschaften im Bemühen um eine Rekonstruktion des Paläoklimas. Es sind dies hauptsächlich Physik, Botanik, Klimatologie, Paläozoologie. Geschichte und ur- und frühgeschichtliche Archäologie (vgl. C. BURGA und G. FURRER, 1982).

Trotz dieser zahlreichen Einzelstudien und Übersichtsarbeiten verbleiben noch viele ungelöste Fragen, die im folgenden lediglich angedeutet werden können. Diese kann man in grundsätzliche und regionale Fragen einteilen.

Zu den grundsätzlichen gehören einmal methodenbedingte Schwierigkeiten, wie Datierungsprobleme und die nur bedingte Vergleichbarkeit der Ergebnisse verschiedener Untersuchungsmethoden. Die Frage nach der Vollständigkeit von Profilen gehört nach wie vor zu den unlösbaren Grundproblemen. Von der absoluten Datierungsmöglichkeit hängt die Altersstellung der würmspäteiszeitlichen Stadiale ab. Die Tatsache, daß heute lediglich das absolute Alter des Egesen-Stadiums als gesichert gelten darf, zeigt, daß für die Datierung der älteren Stadien vermehrt Felduntersuchungen angestrebt werden müssen. Damit verbunden ist die Frage nach der genauen Dauer bzw. dem Beginn, dem Ende und dem Ausma $B$ einer solchen Klimaänderung.

Ebenfalls allgemeiner Art ist der Fragenkreis um den Mechanismus der Klimaänderungen, worüber in letzter Zeit wohl recht zahlreiche Modelle entwickelt wurden (H. FLOHN, 1985), die aber letztlich konkreten Ergebnissen noch zu fern stehen.

Einige dieser hier angedeuteten Probleme dürften wenigstens teilweise, wohl aber mit erheblichem Aufwand mit den heutigen Methoden lösbar sein. Für viele Fragen sind jedoch neue Untersuchungsansätze und -methoden zu entwickeln.

Ein bisher ungelöstes Problem, auf das hingewiesen werden muß, ist einerseits die Verknüpfung des eiszeitlichen Geschehens auf der Alpen-Nordseite und -Südseite, andererseits die Parallelisierung der alpinen mit der nordischen Vereisung.

Die vorliegende Publikation soll Rechenschaft über den gegenwärtigen Stand der vielfältigen Untersuchungen zur spät- und nacheiszeitlichen Geschichte unserer Alpengletscher ablegen, wobei die bisherigen Ergebnisse zu einer weiteren Synthese geführt werden sollen. Sie soll aber auch die noch offenen Fragen und die weiter zu verfolgenden Forschungsansätze aufzeigen. 
2. Zur Gletschergeschichte des alpinen Spätglazials: Analyse und Interpretation von Schneegrenzdaten

(M. Maisch)

\subsection{Einleitung/Zielsetzung}

Neuere Publikationen zur Gletscher- und Klimageschichte des alpinen Spätglazials konzentrieren sich inhaltlich auf drei verschiedenartige, hierarchisch gestufte, aber dennoch eng miteinander verwobene Fragestellungen und Forschungsziele. Zur ersten, weitaus größten Gruppe gehören alle diejenigen Arbeiten, in denen durch das Kartieren und Beschreiben lokaler, zum Teil regionaler Stadien-Sukzessionen versucht wird, das späteiszeitliche Gletschergeschehen morphologisch zu erfassen, vergleichend zu gliedern und wo immer möglich durch punktuelle Datierungen $\left({ }^{1+} \mathrm{C}\right.$-Proben, Pollenanalyse in Torfmooren) chronologisch einzuordnen. Das Entwerfen synoptischer Darstellungen paläogeographischer Vergletscherungssituationen für größere Teilräume des Alpengebietes kann als die zweite dieser Kategorien bezeichnet werden. Dazu hat vor allem die durch die Ausweitung der Untersuchungsgebiete bedingte zunehmende geographische und thematische «Datendichte» geführt (z. B. R. HANTKE, 1983: Stadien-Karte im Anhang; G. FURRER et al., 1984: Stadien-Karte Bündnerland). Zur dritten Gruppe sind alle diejenigen Studien zu zählen, die auf den Ergebnissen oben erwähnter Arbeiten aufbauend versuchen, bestimmten Phänomenen und deren räumlichen Verteilungsmustern glaziologische und zum Teil klimatologische Modellvorstellungen zugrunde zu legen (z. B. W. HÄBERLI, 1982/ 1983: Gletscher-Permafrost-Beziehung; H. KERSCHNER, 1983: Karte der Niederschlagsverteilung während des Egesen-Stadiums).

Als wesentlicher methodischer Bestandteil aller drei Themenbereiche kommt dabei der zahlenmäßigen Erfassung glaziologischer Kenngrößen verschwundener Gletscher große Bedeutung zu. Die Berechnung von "Schneegrenzen" und "Schneegrenz-Depressionen» auf ehemaligen Eisoberflächen (2:1-Flächenteilungsmethode, vgl. G. GROss et al., 1978) gilt heute noch als das gebräuchlichste "Zeichentisch-Verfahren» und hat ohne Zweifel den Weg zu einer klimatologischen Deutung spätglazialer Gletscherausdehnungen geöffnet (vgl. H. HEUBERGER, 1980).

Mit dem vorliegenden, knapp zu haltenden Überblick werden zwei Ziele verfolgt. Zum einen soll anhand von drei Blockdiagramm-Darstellungen die auch im folgenden beschriebene und für die besprochenen Teilräume als typisch erachtete Stadial-Abfolge Gschnitz-Clavadel-Daun-Egesen inklusiv der
Bezugsgröße Hochstand 1850 für die Landschaft Davos (Mittelbünden) plastisch veranschaulicht werden (Fig. 1-3). Zum andern soll der Versuch gewagt sein, Daten aus Schneegrenzberechnungen zusammenfassend auszuwerten, zu interpretieren und einige kritische Bemerkungen daran anzuschließen. Eine umfassendere Abhandlung dieses Teilaspektes (inkl. Tabelle der Original-Werte) sowie auch neuere Ergebnisse sollen einer künftigen Arbeit vorbehalten sein (M. MAISCH, in Vorb.).

Die der vorliegenden Auswertung zugrunde liegenden Schneegrenzdaten für die Stadien Gschnitz-Clavadel-Daun und Egesen wurden folgenden, einheitlich auf der 2:1-Methode basierenden Publikationen (vor allem Universität Zürich) entnommen:

F. BEELER, 1977 (Berninapass), J. SUTER, 1981 (ErrJulier-Gruppe, Oberengadin), M. MAISCH, 1981 (Mittelbünden und Silvrettagruppe, z. T. unpubl.), F. RENNER, 1982 (Gotthard), w. BIRCHER, 1982 (Wallis-Südtäler), H. AESCHLIMANN, 1983 (Mont Blanc Südseite), R. vuagneux, 1983 (Flüelapaß), A.E. VOEGELE, 1984 (Dischmatal), R. BLESS 1984 (Mont Blanc NE-Teil), M. FRANZONi, 1985 unpubl. (Klöntal), U. JORDI, 1987 Univ. Bern (Flims-Pizol), w. WETTER, 1987 (Mont Blanc W-Teil).

Die herausgegriffenen Schneegrenzwerte (2:1Gleichgewichtslinie $=$ GWL, Bezugsniveau $1850=$ BZN, Schneegrenz-Depression $=$ SG-DEP, stadiale Zuordnung) wurden nach geographischen .bzw. klimatologischen Regionen gruppiert (vgl. Tab. 1). Die untersuchte Stichprobe erstreckt sich vom Gebiet des Unterengadins über das Gotthard- bis zum Mont-Blanc-Massiv und enthält damit Werte aus Teilen der Ost- wie auch der Westalpen.

Damit wurde es möglich, der Frage nachzugehen, welchen Einfluß die Lage bzw. die unterschiedlichen klimatischen Bedingungen auf die Höhe der Schneegrenzen und den Betrag der Schneegrenzdepressionen ausüben. Zudem ließe sich abklären, in welchem Ausmaß die Streuung der Einzelwerte auch innerhalb einer als homogen betrachteten Region zu erwarten ist. Es sollten so weitere Argumente und Entscheidungskriterien für die Hypothese erarbeitet werden, ob und unter welchen Voraussetzungen aus unterschiedlichen SG-Depressionsbeträgen regional-paläoklimatische Veränderungen abgeleitet werden dürfen. Unter der Annahme von konstanten Temperatur-Depressionen wären dies vor allem Variationen der Niederschlagsmengen (vgl. H. KERSCHNER, 1982, 1983).

Der Zusammenhang zwischen dem BZN 1850 und der 2:1-GWL der entsprechenden Stadien wurde in der üblichen Form von Regressionsgleichungen dargestellt (Gleichungen 1-4 bzw. Fig. 4-7). Für die Stadien Daun und Egesen wurde zusätzlich die Beziehung zwischen BZN 1850 und der SG-DEP untersucht (Gleichungen 5 und 6 bzw. Fig. 8 und 9). 


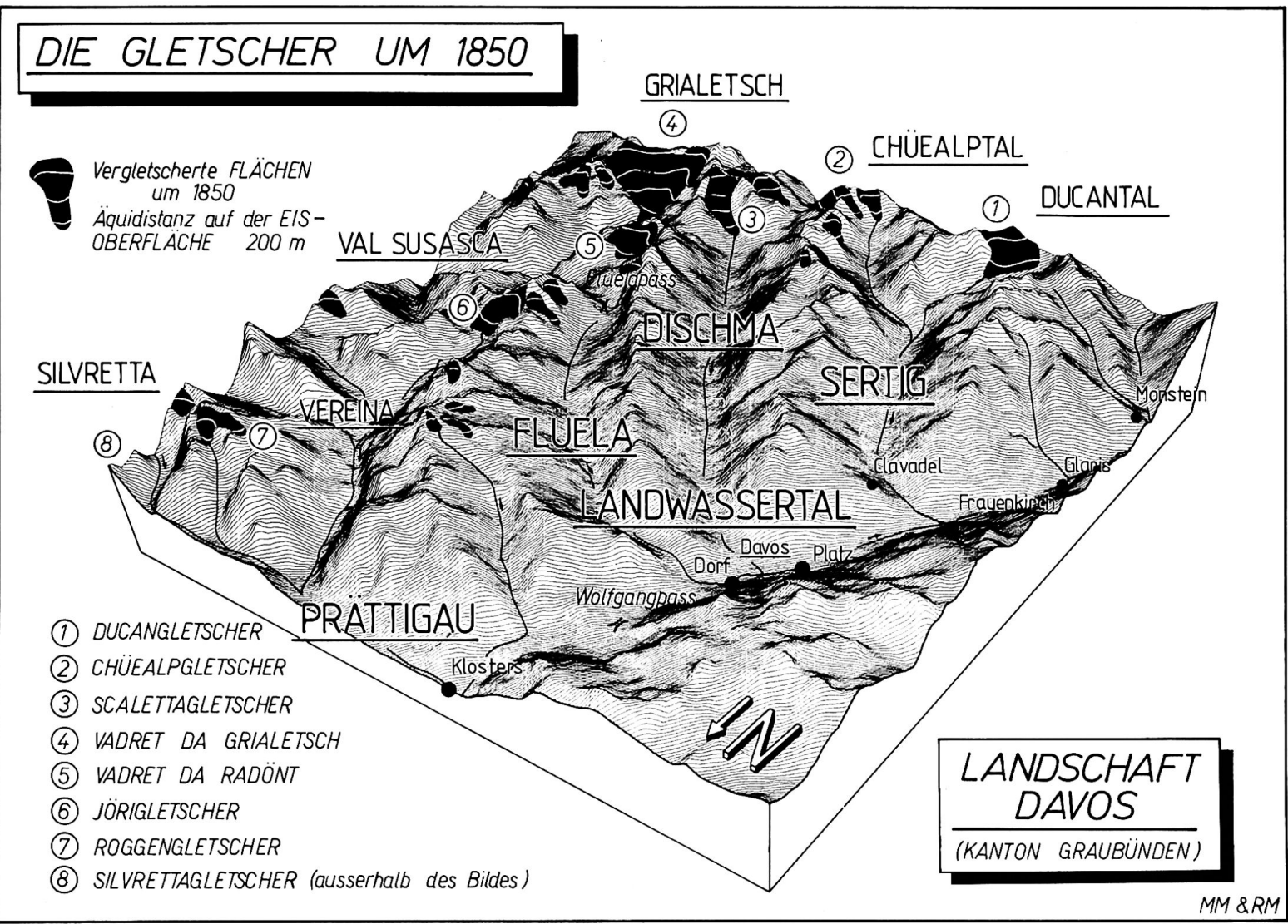

Fig. 1 Geländemodell der Landschaft Davos (Kanton Graubünden): Die Gletscher zur Zeit des Hochstandes von 1850

Fig. 1 Topographic Model of the Davos region (Grisons Alps, Switzerland): the glaciers during the advance of 1850 


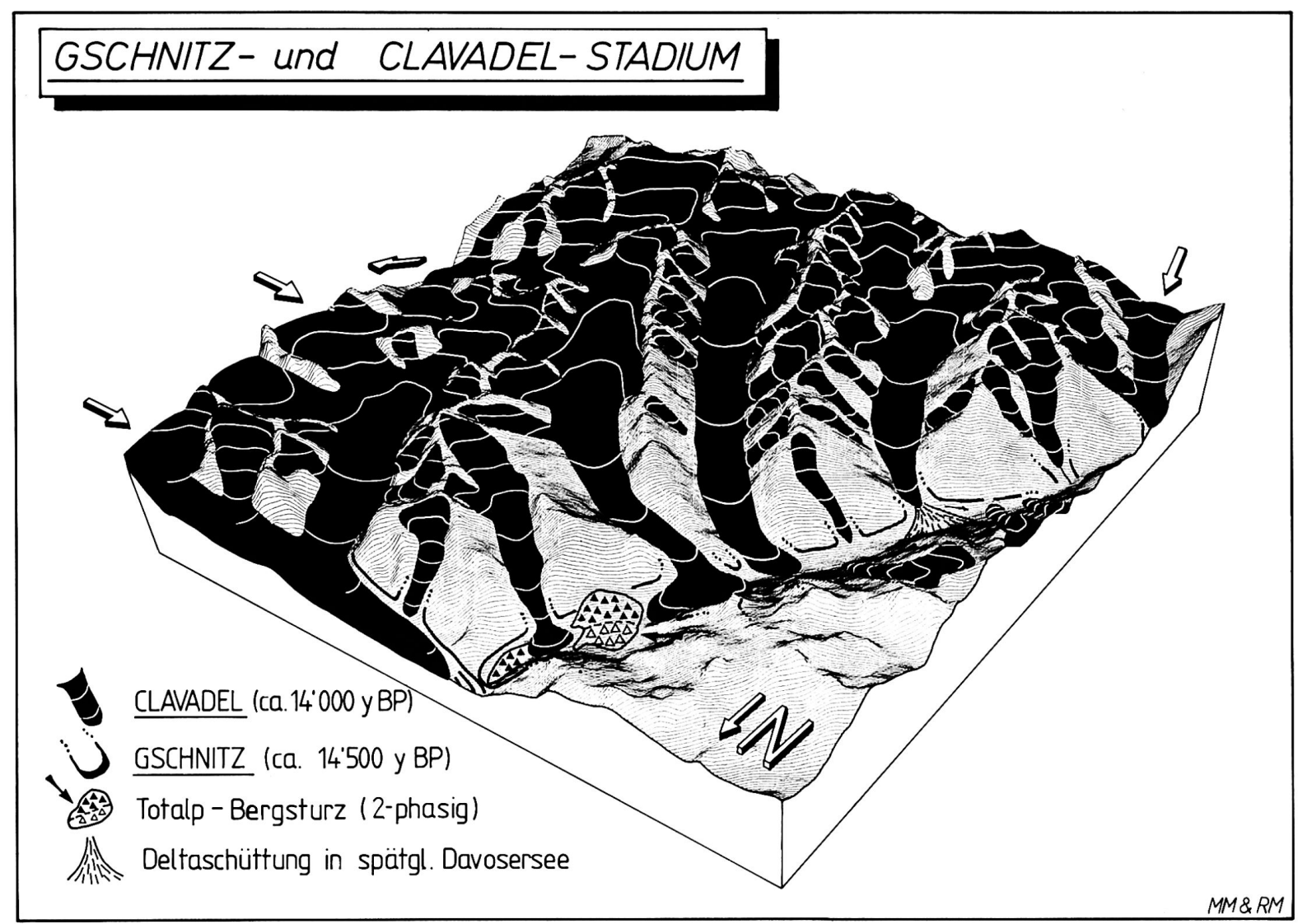

Fig. 2 Die Gletscher-Ausdehnung zur Zeit des GSCHNITZ- und CLAVADEL-Stadiums

Fig. 2 The glacier extension during the GSCHNITZ- (14,500 y BP) and CLAVADEL-Stade (14,000 y BP) 


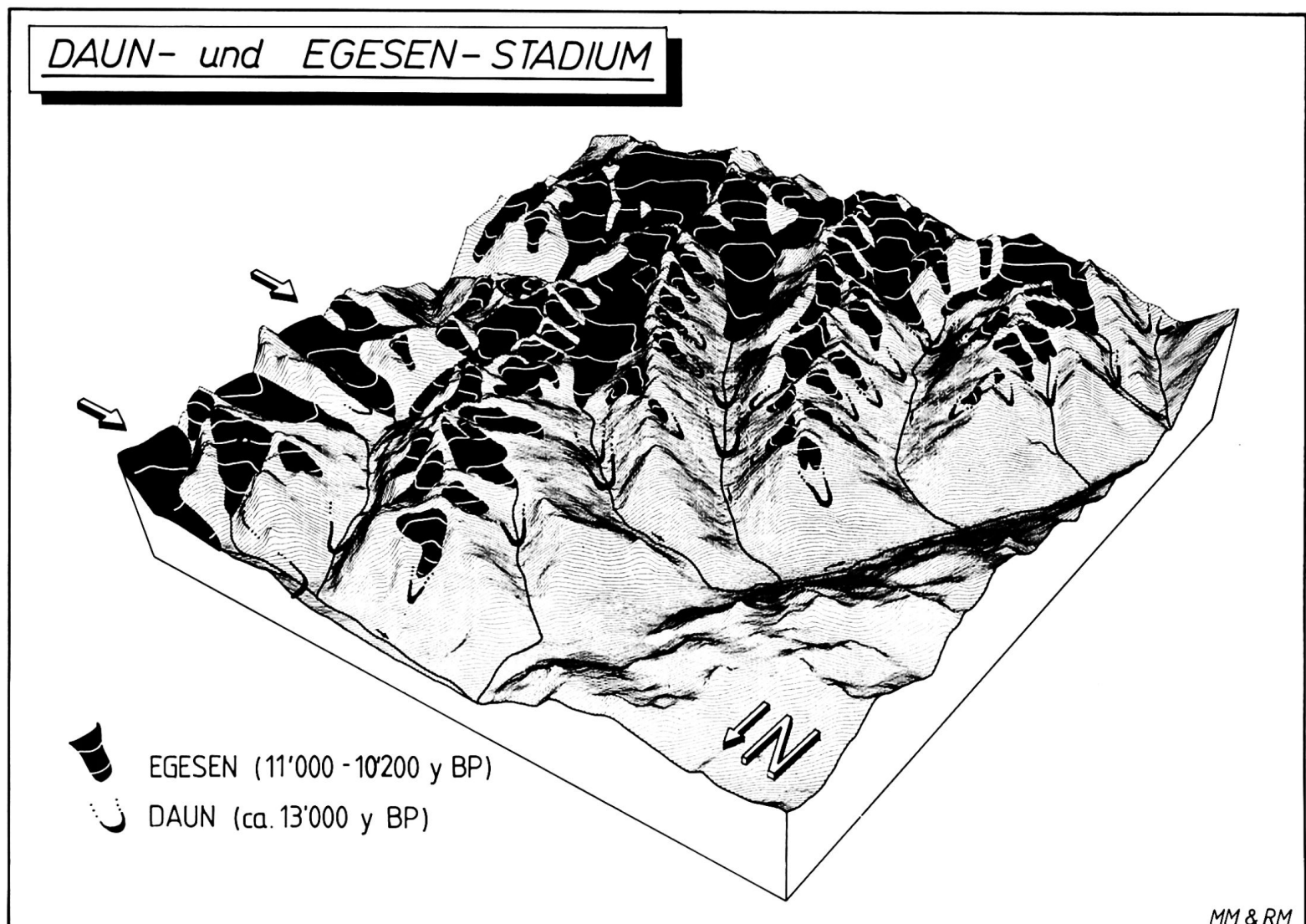

Fig. 3 Die Gletscher-Ausdehnung zur Zeit des DAUN- und EGESEN-Stadiums

Fig. 3 The glacier extension during the DAUN- (13,000 y BP) and EGESEN-Stade (11,000-10,200 y BP) 


\subsection{Interpretation}

Die Graphiken und Tabelle 1 zeigen, daß die Spätglazial-Stichprobe in einigen Teilgebieten eine noch wenig befriedigende Belegungsdichte aufweist. Dieser Umstand beruht allerdings auf der damaligen Vergletscherungssituation. Zur Zeit des Gschnitz- und Clavadel-Stadiums existierten noch ausgedehntere Gletschersysteme mit kompliziert verästelten Einzugsgebieten. Damit war eine verläßliche Rekonstruktion und eine sinnvolle Anwendung der 2:1-Flächenteilungsmethode in vielen Tälern nicht möglich. Daun-und Egesen-Stadium sind naturgemäß - bereits viele kleinere selbständige Lokalgletscher in den Seitentälern - besser dokumentiert und erlauben deshalb gesichertere Aussagen.

Die Regressionsgleichungen 1-4 zeigen nicht ganz unerwartet für alle Stadien hochsignifikante Beziehungen zwischen dem BZN 1850 und der GWL. Es darf dabei aber nicht außer acht gelassen werden. daß die verglichenen Größen nicht im geforderten Maße unabhängig voneinander sind, denn es gilt ja zum vornherein folgende Verknüpfung: BZN $1850-$ GWL $=$ SG-DEP. Der in diesem Zusammenhang für die Interpretation als wesentlich sinnvoller zu erachtende Aspekt der Regressions-Koeffizienten (Steigung der Geraden) zeigt, daß die Werte einschließlich der $99 \%$-Vertrauensbereiche nahe bei 1 , im Durchschnitt sogar leicht über 1 liegen (vgl. Tab. 2). Die Geraden verlaufen damit mehr oder weniger parallel zueinander und deuten bei ansteigendem BZN 1850 eine schwache Tendenz zu höheren GWL- und damit erniedrigten SG-DEP-Werten an. Dieses für klimageographische Schlußfolgerungen relevante Verhalten soll nun für die einzelnen Stadien genauer bewertet werden. Die hinzugefügten ungefähren Altersangaben beruhen auf der Chronologie, wie sie aufgrund der heutigen Datenlage als am wahrscheinlichsten angenommen werden kann (vgl. M. MAISCH, 1982).

Gschnitz-Stadium: ca. 14500 y BP (Gleichung 1)

Die vergleichsweise erhöhte und deutlich über 1 liegende Steigung der Regression ist statistisch wohl signifikant, doch zeigt es sich gerade hier, daß ein "tiefliegender" Einzelwert am Rande einer eher kleinen Stichprobe die Aussage relativ stark beeinflussen kann (Stand «Vorauen» im Klöntal, vgl. M. FRANZONI, 1985). Ein Weglassen dieses morphologisch zumindest im Zungenendbereich zwar sehr markanten, für Schneegrenzberechnungen aber sonst unzuverlässigen Gletscherstandes $(740 \mathrm{~m}$ SG-DEP) senkt die Steigung auf 1,18, reduziert allerdings den Korr.-Koeffizienten auf 0,78 (1\% Irrtumswahrscheinlichkeit). Die tabellierten Werte zeigen zudem die große Variationsbreite der Depressionsbeträge $(600-780 \mathrm{~m})$, so daß die Grenze gegenüber den nächstälteren, schneegrenzmäßig
Tab. 2 Statistische Parameter der Regressionsgleichungen

Tab. 2 Statistical parameters given by the regression-equations

\begin{tabular}{|c|c|c|c|}
\hline Regressionen & $n$ & \begin{tabular}{|l|}
$9 \% \%$ Konfidenzintervalle \\
der Regressionskoeffizienten
\end{tabular} & $\begin{array}{l}\text { Signifikanzniveau der } \\
\text { Korrelationshoefffieienten }\end{array}$ \\
\hline GWL Gsomez & 11 & $1,219-1,327-1.525$ & $0.1 \%$ \\
\hline GWL closoded & 12 & $0,908-1,000-1,092$ & $0.1 \%$ \\
\hline$G W_{\text {Dan }}$ & 46 & $1,031-1,039-1,047$ & $0.1 \%$ \\
\hline $\mathrm{GWL} \mathrm{Egesen}_{\text {E }}$ & 67 & $1.061-1.067-1.073$ & $0.1 \%$ \\
\hline GWL Depr: oan & 46 & $-0,047-0.039--0,031$ & $-10 \%$ \\
\hline GWL Depr. Egesen & 67 & $-0,073-\underline{-0,067}--0,061$ & $-5 \%$ \\
\hline
\end{tabular}

aber immer schwerer faßbaren Stadien (z. B. Steinach-Stadium) als kaum genügend scharf beurteilt werden kann.

Clavadel-Stadium: ca. 14000 y BP (Gleichung 2)

Die Steigung um 1 und die Werteverteilung verdeutlichen, daß die SG-DEP-Werte bei geringer Streuung über sämtliche ausgewiesenen Gebiete als mehr oder weniger konstant angenommen werden können. Damit genügt es für die Zuordnung eines Gletscherstandes dieser Größenordnung eigentlich, die jetzt vorliegenden Kennwerte (Mittel bei $430 \pm 30$. Bandbreite von ca. 385-490 m) als Vergleichskriterium anzuwenden. Die Trennbarkeit gegenüber dem Gschnitz-Stadium ist bisher in allen Fällen gewährleistet, so daß eine Verwechslung als eher unwahrscheinlich gelten kann.

Daun-Stadium: ca. 13000 BP (Gleichungen 3 und 5) Die beiden Graphiken veranschaulichen nun deutlich die bekannte klimageographische Komponente einer Gletscher-Stichprobe. So liegen heutige (und frühere) Gletscher (bzw. ihre GWL und BZN 1850) in niederschlagsreicheren Gebieten am Alpennordhang (Region Flims-Pizol) eher in tieferen Positionen, währenddem solche in inneralpinen, von Niederschlag stärker abgeschirmten Regionen (Engadin, Wallis-Südtäler) eher in höheren, d. h. kälteren Lagen anzutreffen sind. Was die von 1 leicht positiv abweichende Steigung andeutet, kann nun in Gleichung 5 genauer bewertet werden. Es wird bei dieser Gegenüberstellung deutlich, daß die bei ansteigendem BZN 1850, also gegen die trockeneren Gebiete hin schwach erkennbare Tendenz zu erniedrigten Depressionswerten statistisch als nicht signifikant betrachtet werden muß (über $10 \%$ Irrtumswahrscheinlichkeit, vgl. Tab. 2). Damit kann die be- 


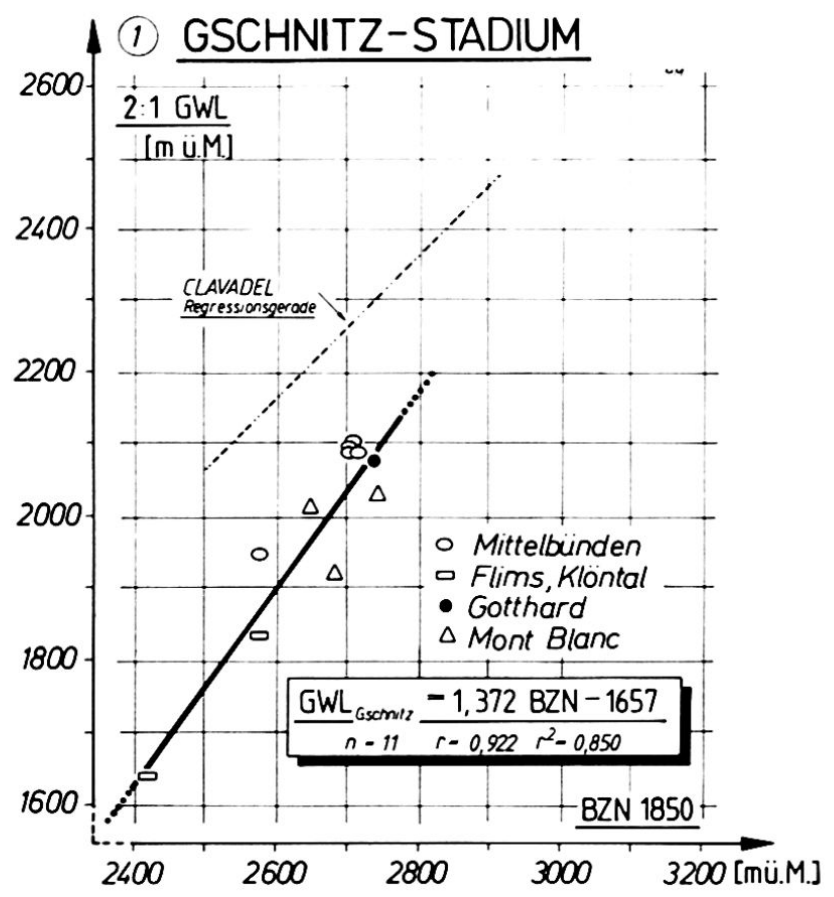

Fig. 4 Regressionsdiagramm zwischen der Gleichgewichtslinie des GSCHNITZ-Stadiums und dem Hochstand 1850 (Bezugsniveau)

Fig. 4 Regression diagram: equilibrium line altitude of the GSCHNITZ-Stade (2:1-GWL) and the 1850-advance (BZN 1850)

\section{(3) DAUN-STADIUM}

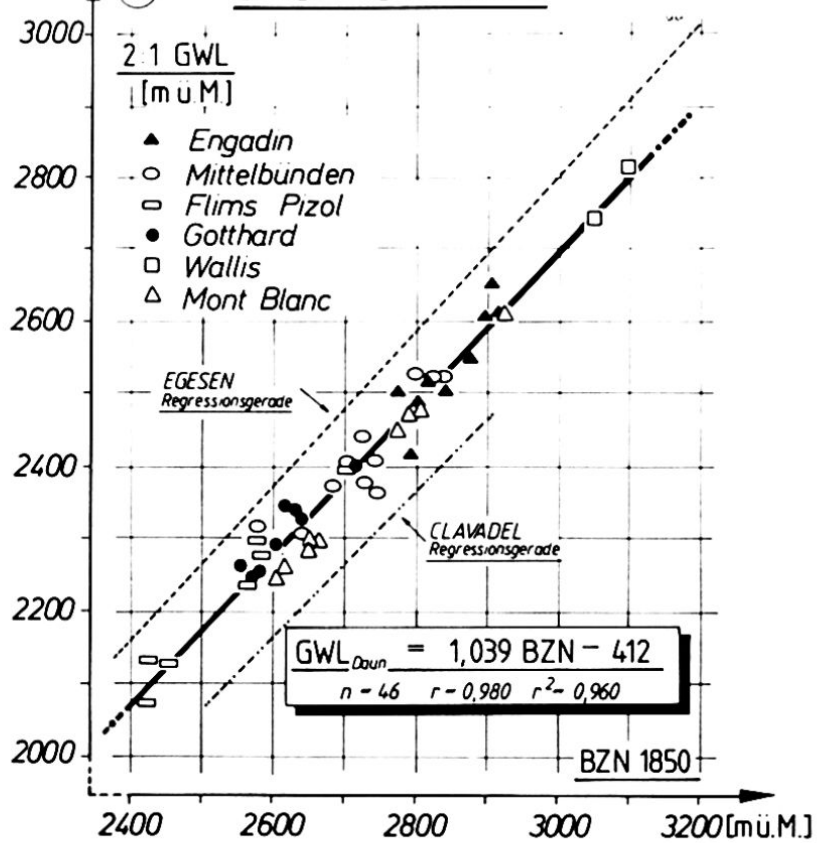

Fig. 6 Regressionsdiagramm zwischen der Gleichgewichtslinie des DAUN-Stadiums und dem Hochstand 1850 (Bezugsniveau)

Fig. 6 Regression diagram: equilibrium line altitude of the DAUN-Stade (2 : 1-GWL) and the 1850-advance (BZN 1850)

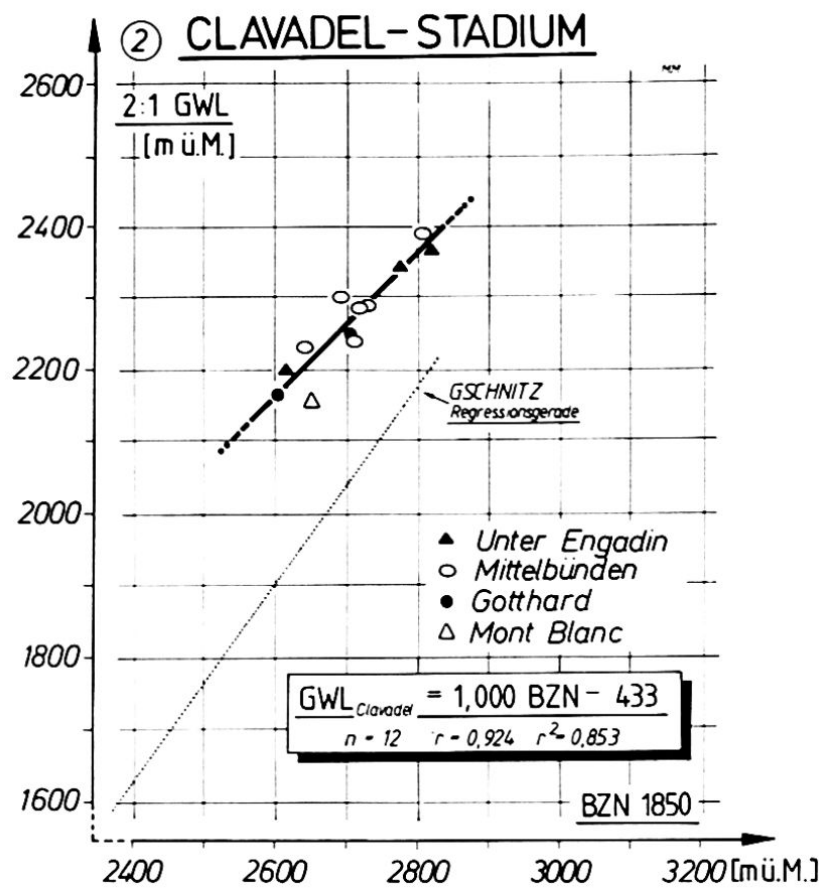

Fig. 5 Regressionsdiagramm zwischen der Gleichgewichtslinie des CLAVADEL-Stadiums und dem Hochstand 1850 (Bezugsniveau)

Fig. 5 Regression diagram: equilibrium line altitude of the CLAVADEL-Stade (2:1-GWL) and the 1850-advance (BZN 1850)

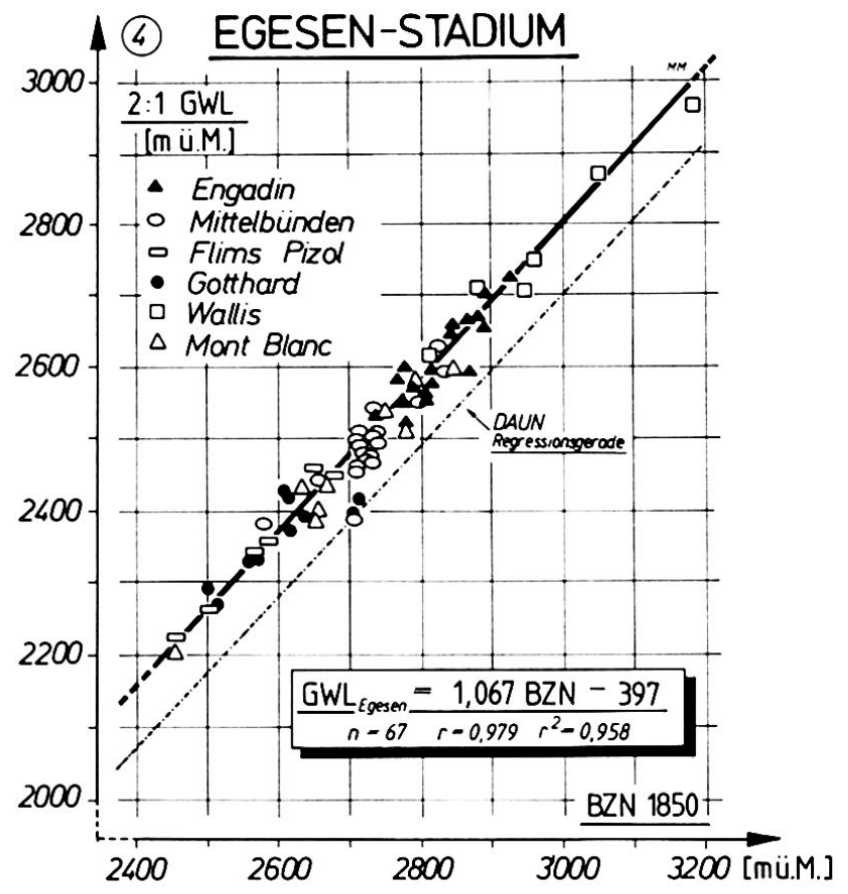

Fig. 7 Regressionsdiagramm zwischen der Gleichgewichtslinie des EGESEN-Stadiums und dem Hochstand 1850 (Bezugsniveau)

Fig. 7 Regression diagram: equilibrium line altitude of the EGESEN-Stade (2:1-GWL) and the 1850-advance (BZN 1850) 
(5) DAUN-STADIUM

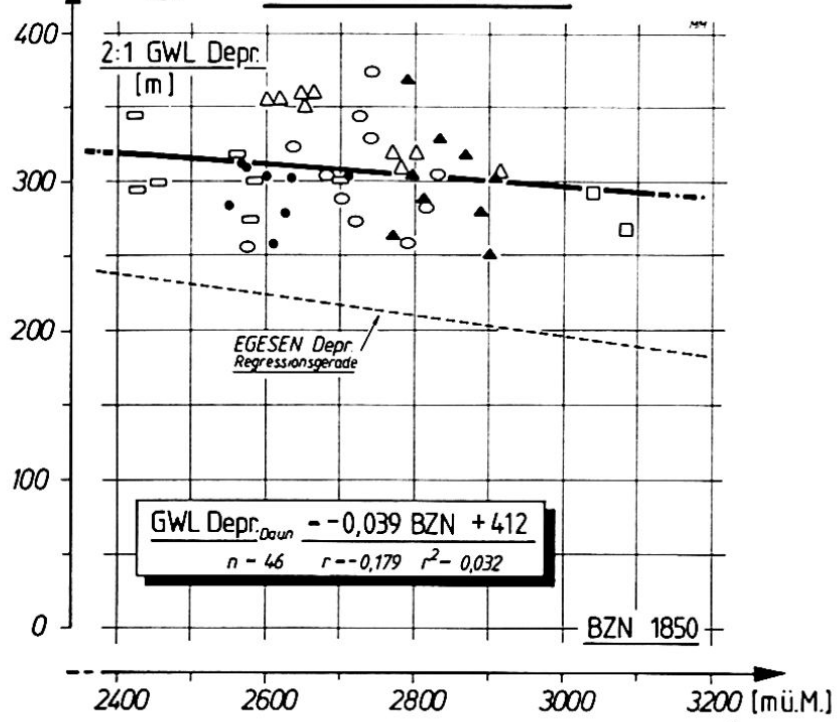

Fig. 8 Regressionsdiagramm zwischen der SchneegrenzDepression des DAUN-Stadiums und dem Hochstand 1850 (Bezugsniveau)

Fig. 8 Regression diagram: snowline depression of the DAUN-Stade (2:1-GWL-Depr.) and the equilibrium line altitude of the 1850-advance (BZN 1850)

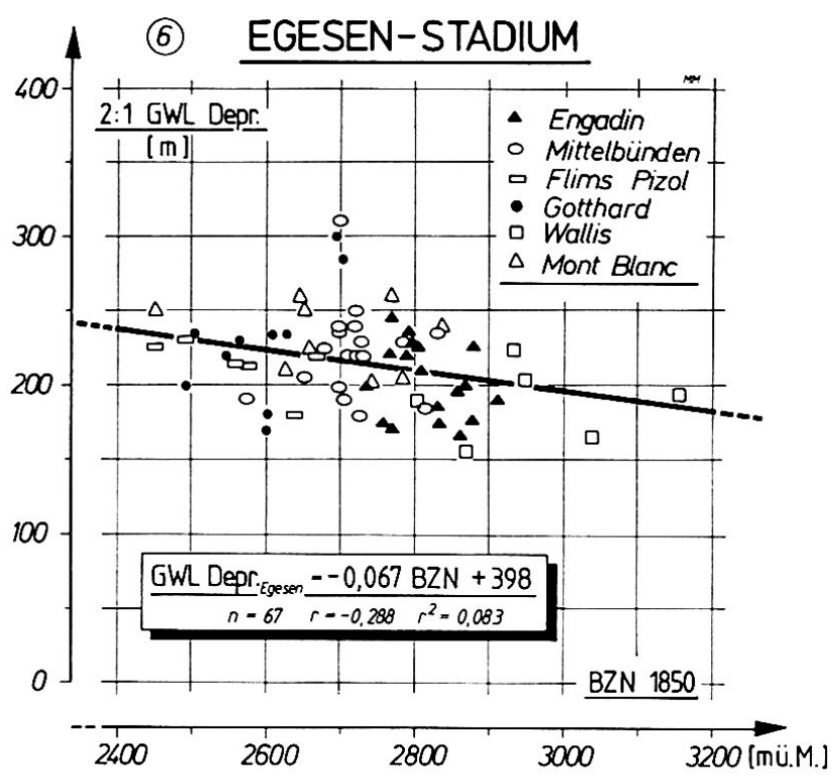

Fig. 9 Regressionsdiagramm zwischen der SchneegrenzDepression des EGESEN-Stadiums und dem Hochstand 1850 (Bezugsniveau)

Fig. 9 Regression diagram: snowline depression of the EGESEN-Stade (2:1-GWL-Depr.) and the equilibrium line altitude of the 1850-advance

Tab. 1 Tabellarischer Vergleich der Schneegrenz-Depressionen des GSCHNITZ-, CLAVADEL-, DAUN- und EGESEN-Stadiums in den verschiedenen Gebieten der Alpen

Tab. 1 Summary table with values for snowline depression calculated for the stades of GSCHNITZ, CLAVADEL, DAUN and EGESEN in different regions of the Alps

Vergleich der SCHNEEGRENZDEPRESSIONEN

\begin{tabular}{|c|c|c|c|c|c|c|c|c|c|c|c|c|}
\hline STADIALE: & \multicolumn{3}{|c|}{ GSCHNITZ } & \multicolumn{3}{|c|}{ CLAVADEL } & \multicolumn{3}{|c|}{ DAUN } & \multicolumn{3}{|c|}{ EGESEN } \\
\hline Gletscherregion & $n$ & $\begin{array}{|ll|}\bar{x} & \sigma \\
\end{array}$ & Min-Max. & $n$ & $\begin{array}{|ll|}\mathrm{z} & \sigma \\
\end{array}$ & Min-Max. & $n$ & $\begin{array}{ll}\mathrm{x} & \sigma \\
\end{array}$ & Min-Max. & \begin{tabular}{l|l}
$n$ \\
\end{tabular} & \begin{tabular}{|ll}
$\bar{x}$ & $\sigma$ \\
\end{tabular} & Min-Max. \\
\hline Engadin & - & -- & -- & 3 & $425 \pm 20$ & $410-450$ & 9 & $300 \pm 35$ & $250-370$ & 18 & $200 \pm 25$ & $170-245$ \\
\hline Mittelbünden 0 & 5 & $615 \pm 15$ & $600-630$ & 6 & $420 \pm 30$ & $385-465$ & $\pi$ & $305 \pm 35$ & $255-375$ & 18 & $225 \pm 30$ & $180-310$ \\
\hline Flims Pizol & 2 & $760-$ & $740-780$ & - & -- & $-\quad-$ & 7 & $305 \pm 20$ & $275-345$ & 6 & $210 \pm 20$ & $180-225$ \\
\hline Gotthard & 1 & $660-$ & -- & 2 & $440-$ & $435-450$ & 8 & $295 \pm 20$ & $260-315$ & 10 & $230 \pm 40$ & $180-300$ \\
\hline Wallis & - & -- & -- & - & -- & -- & 2 & $280-$ & $270-295$ & 6 & $190 \pm 25$ & $155-225$ \\
\hline Mont Blanc $\triangle$ & 3 & $700 \pm 65$ & $635-760$ & 1 & $490-$ & 490 & 9 & $335 \pm 25$ & $305-360$ & 9 & $235 \pm 25$ & $200-260$ \\
\hline TOTAL & 11 & $670 \pm 65$ & $600-780$ & 12 & $430 \pm 30$ & $385-490$ & 46 & $310 \pm 30$ & $255-375$ & 67 & $215 \pm 30$ & $155-310$ \\
\hline & & & & & & & & & & & $\begin{array}{l}\text { Angaben } \\
\text { verte auf }\end{array}$ & $\begin{array}{l}\text { in Metern } \\
\text { im gerundet }\end{array}$ \\
\hline
\end{tabular}


obachtete Punktverteilung nicht hinreichend mit der (Höhen-)Lage der Gletscher erklärt werden, und eine Differenzierung der Daten nach klimageographischen Gesichtspunkten scheint damit außer Betracht zu fallen.

Egesen-Stadium: $11000-10200$ y BP (Gleichung 4 und 6)

Die Geraden des Egesen-Maximalstandes zeigen, verglichen mit dem Daun-Stadium, ein durchaus ähnliches, in bezug auf die leicht erhöhte Steigung in Gleichung 4 resp. die leicht fallende Tendenz in Gleichung 6 aber leicht akzentuiertes Verhalten bei statistisch besser abgesicherten Parametern. Beurteilt man aber nun die bei einem BZN von $2400 \mathrm{~m}$ bzw. $3000 \mathrm{~m}$ zu erwartenden DEP-Werte (237 bzw. $197 \mathrm{~m} / \mathrm{BZN} 1850$ ), so kann angesichts der graphisch leicht abzuschätzenden großen Residualstreuung diese mittlere Depressionsdifferenz kaum als Ausgangspunkt für weiter darauf aufbauende klimatologische Schlußfolgerungen verwendet werden.

Auffallend sind zusätzlich die zum Teil recht großen Variationsbereiche der SG-DEP-Beträge, die zumindest in Einzelfällen zu Überschneidungen mit dem Daun-Stadium führen können. Eine Analyse dieser Residualwerte zeigt, daß sich bei diesen «Extremgletschern" eine oder mehrere Grundvoraussetzungen ungünstig kumulieren, wie $\mathrm{z}$. B. das Vorhandensein von Gefällsknicken im Gletscherbett, übersteile Talflanken im Nährgebiet, Unsicherheiten bei der zeichnerischen Rekonstruktion usw. Bei diesen Gletschern kann aber zumeist festgestellt werden, da $\beta$ unter diesen Voraussetzungen sowohl die Werte für Egesen wie auch für Daun erhöht sind (z. B. Dischmatal: 310 bzw. 375 m SG-DEP, A.E. VOEGELE, 1984). Eine schneegrenzmäßige Trennung dieser nach morphologischen Kriterien separierten Stände bleibt damit zwar gewährleistet. Nur scheidet eine klimabedingte Ursache (z. B. erhöhter Niederschlag) für diese gesamthaft erhöhten DEP-Beträge hier als Erklärung aus, zumal die äquivalenten Daun/Egesen-Stände gerade in den ähnlich exponierten Nachbartälern Sertig (Chüealpgletscher: 290/235 m, Ducangletscher 275/240 m, vgl. M. MAISCH, 1981) und Flüela (Flüelagletscher: $330 / 250 \mathrm{~m}$, vgl. R. VUAGNEUX, 1983) wieder durchaus in der Norm liegende Werte zeigen.

Wenn man davon ausgeht, daß die von den einzelnen Autoren getroffene stadiale Zuordnung stimmt, so bestätigen solche aus dem Rahmen fallende Einzelwerte den Eindruck, daß Variationen und selbst größere Abweichungen von Schneegrenzen und SGDepressionen durchaus "natürlich" sind und die Summe oder das Produkt aller mit der 2:1-Methode direkt oder indirekt verknüpften Randbedingungen und Beeinflussungsfaktoren darstellen. Dabei soll- ten selbst Variationen des "durchschnittlichen», glaziologisch begründeten 2:1-Flächenverhältnisses zwischen Akkumulations- und Ablationsgebiet nicht ganz außer acht gelassen werden. Es wäre sogar sinnvoll, bei Schneegrenz-Abschätzungen z. B. durch die Angabe von Minimal- und Maximalwerten der SG-DEP bei variabel gewählten Teilungsverhältnissen zwischen etwa 1,5 und 2,5-diesen Aspekt als Argument und Zuordnungskriterium stets mitzuberücksichtigen (vgl. S. BADER, 1986).

\subsection{Schlußfolgerungen}

Die Auswertung der vorliegenden Spätglazial-Stichprobe, die als die bisher umfangreichste ihrer Art gelten kann, veranlaßt zu folgenden Überlegungen und Bemerkungen:

- Die aus verschiedenen Arbeiten gesammelten Daten zeigen, da $\beta$ die Verteilung der Gletscher nach ihrer (Höhen-)Lage wohl grob die regionalklimatischen Verhältnisse widerspiegelt (Zusammenhang «Temperatur-Niederschlag», Einfluß der Abschirmung und Massenerhebung).

- Aufgrund der statistischen Analyse ergeben sich keine zwingenden Gründe, die zwischen den einzelnen Gletscherregionen nur wenig differierenden SG-DEP-Werte und -Bandbreiten als Ausdruck unterschiedlicher, v. a. niederschlagsbedingter klimageographischer Variationen (z. B. während des Egesen-Stadiums) zu interpretieren.

- Vielmehr scheinen die vorhandenen Streuungen und die nur schwach erkennbaren Trend-Verläufe das Resultat von zufälligen, natürlichen externen (z. B. Relief-Faktoren) und internen, methodenbedingten (2:1-Flächenteilung) Voraussetzungen zu sein.

- Für die Annahme von "Depressionsgradienten» von den eher feuchten randalpinen zu den trockeneren inneralpinen Gletschergebieten, wie dies von G. GROSS et al. (1978) und H. KERSCHNER (1983) aufgrund einer wesentlich kleineren Stichprobe fürTeile der Ostalpen postuliert wird - und eigentlich ein altes Anliegen darstellt (vgl. A. PENCK und E. BRUCKER, 1909) --, können für die hier untersuchten Gletscherregionen keine stichhaltigen Argumente gewonnen werden. Möglicherweise sind DEP-Werte aus den feucht-randalpinen Gebieten etwas untervertreten.

- Der Trend zu einer räumlichen Differenzierung von Schneegrenzdepressions-Beträgen ist damit nicht widerlegt, doch bleibt er unter der offenbar bisher kaum berücksichtigten Individual-Streuung eines jeden Gletschers (und auch des Interpretations-Spielraumes eines jeden Bearbeiters!) verborgen und/oder wird, da sehr gering, mit wachsender Stichprobengröße verwischt. 
- Als Konsequenz sollten Schneegrenzberechnungen und darauf aufbauende Interpretations-Versuche wieder vermehrt kritisch beurteilt und weniger dogmatisch gehandhabt werden. Zirkelschlüsse, daß man aufgrund zu eng gefaßter Vorstellungen über das Ausmaß der möglichen Streubreite von SG-Depressionen neue Stadien einführt oder bei tatsächlich vorhandenen klimabedingten Abweichungen allein aufgrund der DEPWerte Stadien verwechselt (v. a. Daun und Egesen), sollten möglichst vermieden werden.

\section{Dank}

Ich danke an dieser Stelle ganz herzlich ROBERTO MAZZONI (stud. geogr., Davos/Zürich) für die zuvorkommende Hilfe bei der Auswahl und Optimierung des Geländemodell-Ausschnittes. Ebenfalls bedanke ich mich bei DR. UELI JORDI (Chur) und DR. WOLFGANG WETTER (Schaffhausen) für den gewährten Einblick in ihre noch unveröffentlichten Schneegrenzdaten sowie unserem Instituts-Graphiker MARTIN STEINMANN für seine Hilfe bei den Repro-Arbeiten.

\section{Vegetationsgeschichte seit der Späteiszeit (C. Burga)}

\subsection{Problemstellung, Methodisches}

Die Erforschung der Vegetationsgeschichte bringt Hinweise zur Paläoklimatologie, Florengeschichte, ehemalige natürliche Zusammensetzung der Waldvegetation und zur Waldgrenze, besonders die klimatisch und anthropogen bedingten Schwankungen und die Maximalhöhe.

Ferner ist die Pollenanalyse ein Mittel zur biostratigraphischen Gliederung quartärer und auch älterer Sedimente sowie ein bisweilen in der Gletschergeschichte angewandte Methode.

Als einige noch ungelöste Probleme zur Pollenanalyse als Methode und zur Erforschung der Vegetationsgeschichte seien folgende Gesichtspunkte stichwortartig genannt:

- Spezielle lokale und regionale Vegetationsentwicklung und feinere Datierung

- Höhenstufenentwicklung der Vegetation (Fehlen geeigneter Moore in allen Stufen)

- Die Rolle der Fernflug- und Umlagerungspollen (vgl. U. GRONER, 1986)

- Klimaschwankungen und ihr Ausmaß (Dauer und Wirkung von Klimaschwankungen auf die Vegetation)
- Standörtliche Unterschiede und Vegetationsentwicklung (Boden, Geologie)

- Einwanderung und Ausbreitung einzelner Baumarten (nur für einige Taxa lokal bis regional bekannt)

- Klimatische und menschliche Beeinflussung der Vegetation

- Moorbildungsphasen (Datierung, vgl. F. OVER. BECK, 1975; G. GROSSE-BRAUCKMANN, 1976: K. FAEGRI Und J. IVERSEN, 1975)

- Feinere Bestimmung und Auswertung von Krautpollentypen

- Auswertung von Makroresten (Bestimmbarkeit)

- Kontext von Vegetations- und Gletschergeschichte

Das pollenanalytisch ermittelte Bild zur ehemaligen Vegetation kann bisweilen sehr verzerrt sein. Nur durch interdisziplinäre Untersuchungen können Paläovegetation und Paläoklima rekonstruiert werden. Eine gut fundierte Waldgeschichte der Schweiz seit der ausgehenden letzten Eiszeit kann heute noch nicht geschrieben werden. Derzeit sind wir erst punkt- und fleckenweise über die lokale und regionale Waldgeschichte orientiert. Oft weiß man nur um die regionale Geschichte einer einzelnen waldbildenden Baumart. Über die prozentuale, quantitative Zusammensetzung unserer Wälder ist so gut wie nichts bekannt. Alle bisherigen pollenanalytischen Untersuchungen ergaben durchwegs qualitative Resultate. So kann die Geschichte der Schweizer Vegetation vorläufig nur durch Punktkarten dargestellt werden.

Man findet selten vollständige Profile mit bester Pollenerhaltung, sondern Hiaten, Verdoppelungen, schlecht konservierte Pollen, in den älteren Profilabschnitten oft Umgelagerte, wodurch die Profile nur schwer zu interpretieren sind.

Ein regelmäßiges Netz von Untersuchungsstellen ist deshalb auch aus geomorphologischen Gründen nicht möglich. Wir sind auf eher zufällige Stichproben angewiesen, von denen auf größere Regionen bedingt extrapoliert werden muß. Ferner sind wir auf Referenz-Profile angewiesen, in denenTeilinformationen hineinpassen. Je mehr kongruente Teilinformationen aus demselben Landschaftsgebiet stammen, um so sicherer und detaillierter kann die Landschafts- bzw. Vegetationsgeschichte rekonstruiert werden. Speziell sei noch auf den Kontext zwischen Sauerstoffisotopen- und Pollenanalysen verwiesen (U. EICHER, 1979), wo sehr interessante Ergebnisse zum Paläoklima und zur Paläogeographie bereits vorliegen und noch weiter zu erwarten sind. Eine Übersicht zu den paläoklimatologischen Methoden gibt G. LANG (1985). Zu den diesbezüglichen Indikatoren und ihren Zeigerwert vgl. B. FRENZEL (1980). 

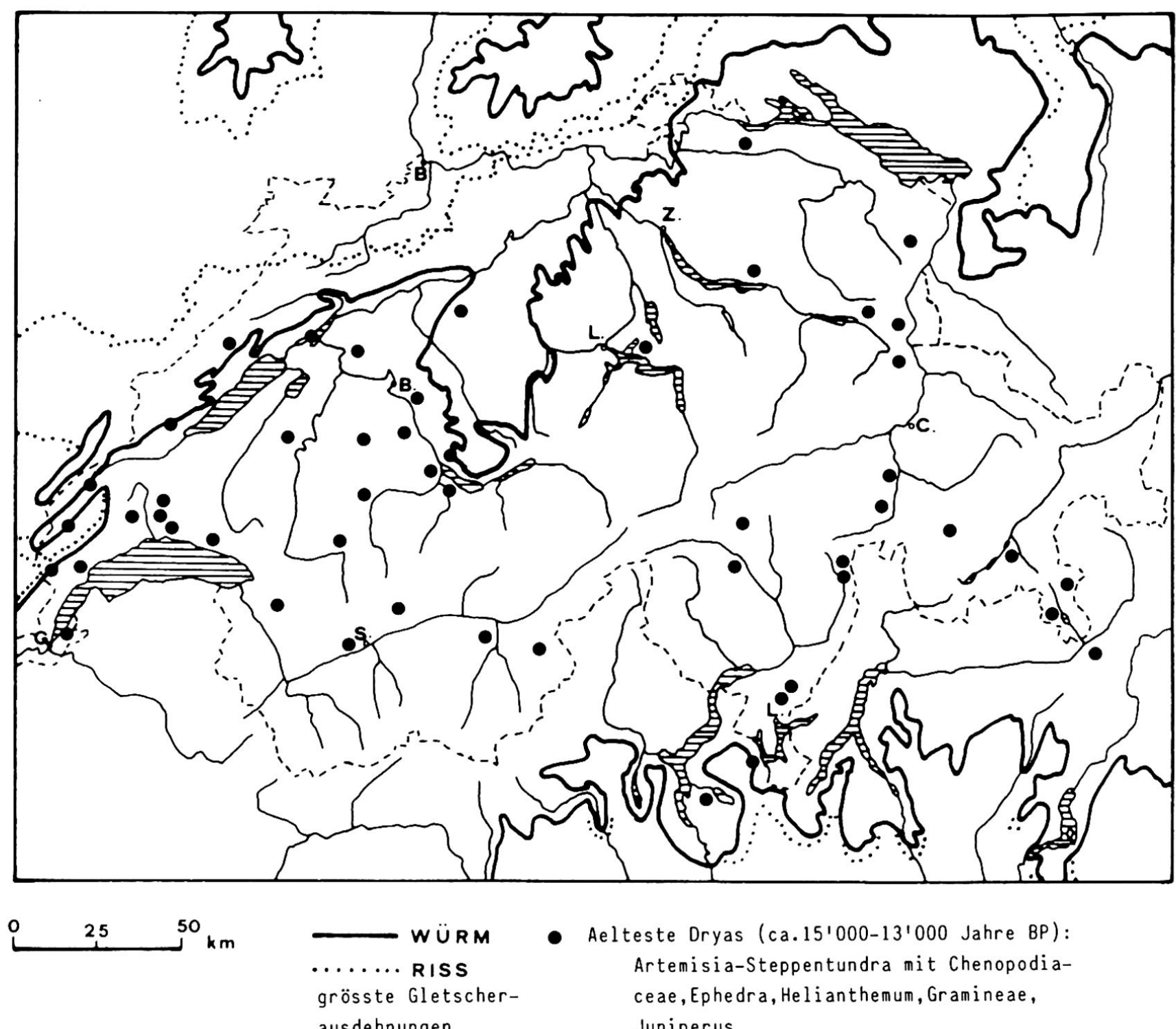

- Aelteste Dryas (ca.15'000-13'000 Jahre BP): Artemisia-Steppentundra mit Chenopodiaceae, Ephedra, Helianthemum, Gramineae, Juniperus

Fig. 10 Riß- und würmeiszeitliche Gletscherausdehnungen und Fundpunkte zur Ältesten Dryas-Zeit in der Schweiz

Fig. 10 Riss and Würmian glacier extensions and localities with the Oldest Dryas zone in Switzerland

\subsection{Forschungsgeschichtlicher Überblick (vgl. Übersichten 1-3)}

Nachfolgende Zusammenstellungen der wichtigsten publizierten pollenanalytischen Untersuchungen zur Vegetationsgeschichte der Schweiz seit dem Würm-Spätglazial sollen einen forschungsgeschichtlichen Überblick vermitteln. Die Arbeiten wurden in die drei Gruppen «Würm-Spätglazial». «Postglazial» und "Zusammenfassende Darstellungen" aufgeteilt, wobei mehrere Arbeiten zweimal erscheinen, da sie Profile vom Spät- bis zum Postglazial enthalten.

Die landschaftliche Gliederung der Arbeiten in Jura. Mittelland, Alpen und Südschweiz zeigt deutlich die sehr unterschiedliche Untersuchungsdichte in diesen Regionen. Zum dichtesten untersuchten Gebiet gehören die Alpen und das Mittelland mit etwa je 30 wichtigen Publikationen. Der Jura und die Südschweiz fallen deutlich ab mit ca. je 7 Arbeiten. Diese Unterschiede liegen wohl nicht primär im Interesse der betreffenden Bearbeiter begründet, sondern vor allem in den topographischen, klimatischen und anthropogenen Bedingungen der verschiedenen Regionen. Das Hochgebirge ist bekanntlich reicher an ökologischen Nischen, so daß wesentlich mehr kleinere Moorobjekte vorzufinden sind. Ferner sind diese vermehrt vor dem menschlichen Eingriff verschont geblieben. Das Inventar der Hoch- und Übergangsmoore der Schweiz von A. GRÜNIG, L. VETTERLI und O. WILDI (1986) zeigt, daß die gegenwärtige Hochmoorfläche von 


\section{Übersicht 1 Würm-Spätglazial ALPEN}

C. BURGA (1980, 1984, 1987): Hinterrhein, Misox, Puschlav, südrätische Alpen

U. EICHER (1979): Faulenseemoos usw.

K. HEEB u. M.WELTEN (1972): Schwarzenegg, Linden, Wachseldorn

A. K. HEITZ (1982): Oberengadin, Maloja

C. HEITZ (1975): Oberhalbstein

H. KLEIBER (1974): Oberengadin, Maloja

M. KÜTTEL (1974, 1977, 1979): Berner Oberland, Wallis

G. LANG u. K. TOBOLSKI (1985): Hobschensee, Simplon

V. MARKGRAF (1969): Wallis

H. J. MÜLLER (1972): Vorderrheintal, Lukmanier

P.PUNCHAKUNNEL (1982): Oberengadin, St. Moritz

H.P. WEGMÜLLER (1976): Voralpen, Prättigau

M. WELTEN (1944, 1952, 1958, 1972, 1977, 1982a, b): Berner Oberland, Simmental, Voralpen, Wallis, Nationalpark

H. ZOLLER et al. (1966): Göscheneralp

\section{JURA}

A. EBERHARDT u. C. KRÄHENBÜHL (1952): Pontins sur St-Imier

A. ISCHER (1935): Ponts-de-Martel

F. MATTHEY (1971): Jura central (NE)

S. WEGMÜLLER (1966): Südwest-Jura

\section{MITTELLAND}

B. AMMANN (1975, 1983): Bielersee, Lobsigensee

U. EICHER (1979): Gerzensee usw.

M.-J. GAILLARD et al. (1981): Lac Léman

M.-J. GAILLARD (1984): Moyen-Pays Romand

R. HÄNI (1964): Lobsigensee

A. LOTTER (1985): Amsoldingersee/Thun

W. LÜDI (1935): Großes Moos

W. LÜDI (1957): Zürichsee

M. RÖSCH (1983): Nußbaumer Seen

C. SIDLER (1984): Zürichsee

S. WEGMÜLLER (1980): Seeland

M. WELTEN (1974, 1979, 1982a): Burgäschisee, Aaretal, östl. Mittelland

R. ZWAH'.EN (1985): Lörmoos/Bern

\section{SÜDSCHWEIZ}

W. LÜDI (1944): Südtessin

R. SCHNEIDER (1985): Lago di Ganna/Varese (Italien)

H. ZOLLER (1958, 1960a, 1963): Misox, Leventina, Südtessin

H. ZOLLER u. H. KLEIBER (1971): Misox, Leventina, Sottoceneri

\section{Übersicht 2 Postglazial \\ ALPEN}

C. BURGA (1980, 1984, 1987): Hinterrhein, Bernhardin, Misox, Puschlav, südrätische Alpen

U. EICHER (1979): Faulenseemoos usw.

K. HEEB u. M. WELTEN (1972): Voralpen

A. K. HEITZ (1982): Oberengadin

C. HEITZ (1975): Oberhalbstein

A. HOFFMANN $(1943,1946,1957)$ : Glarner Alpen

P. KELLER (1928, 1930, 1935): Voralpen, Graubünden, Wallis

H. KLEIBER (1974): Oberengadin

M. KÜTTEL (1974, 1977, 1979): Berner Oberland, Wallis

G. LANG u. K. TOBOLSKI (1985): Hobschensee, Simplon

V. MARKGRAF (1969): Wallis

H. J. MÜLLER (1972): Vorderrheintal, Lukmanier

P. MÜLLER (1949): Pilatus

P. PUNCHAKUNNEL (1982): Oberengadin, St. Moritz

H. P. WEGMÜLLER (1976): Voralpen, Prättigau

M. WELTEN (1944, 1952, 1958, 1977, 1982a): Berner Oberland, Simmental, Wallis, Nationalpark

H. ZOLLER et al. (1966): Göscheneralp

\section{JURA}

A. EBERHARDT u. C. KRÄHENBÜHL (1952): Pontins sur St-Imier

F. HUBSCHMID (1985): Les Embreux, Freiberge

A. ISCHER (1935): Ponts-de-Martel

M. JORAY (1942): Etang de la Gruère

P. KELLER (1928): Freiberge

F. MATTHEY (1971): Jura central (NE)

H. SPINNER (1930): La Brévine

\section{MITTELLAND}

B. AMMANN (1975, 1983): Bielersee, Lobsigensee

U. EICHER (1979): Burgäschisee usw.

M.-J. GAILLARD (1981, 1984): Lac Léman, Moyen-Pays Romand

R. HÄRRI (1940): Wauwilermoos

A. K. HEITZ (1976, 1977, 1978): Zürichsee

N. HUFSCHMID (1983): Zürichsee

P. KELLER (1928): nördl. Mittelland, Ostschweiz

H. LIESE-KLEIBER (1976, 1977, 1982): Neuenburger-.See

A. LOTTER (1985): Amsoldingersee/Thun

W. LÜDI (1935a, 1939): Großes Moos, Sihltal bei Einsiedeln, Lac de Genève

C. REYNAUD (1981, 1982): Région lémanique

M. RÖSCH (1983): Nußbaumer Seen

P. VILLARET (1965): Région lémanique

S. WEGMÜLLER (1980): Seeland

R. ZWAHLEN (1985): Lörmoos/Bern

\section{SÜDSCHWEIZ}

P. KELLER (1930): südliches Tessin

W. LÜDI (1944): Südtessin

R. SCHNEIDER (1985): Lago di GannaNarese (Italien)

H. ZOLLER (1958, 1960a, 1963): Misox, Leventina, Südtessin H. ZOLLER u. H. KLEIBER (1971): Misox, Leventina, Sottoceneri 


\section{Übersicht 3 Zusammenfassende Darstellungen}

Vegetationsgeschichte E. FURRER (1927), G. LANG (1985a, b), P.STARK (1929), W. RYTZ (1949), F. KRAL (1979), der Schweiz allg. H. ZOLLER (1962, 1968), H. ZOLLER u. H. KLEIBER (1971b)

Vegetationsgeschichte C. BURGA (1980): Picea, (1982b): Ephedra; P. KELLER (1932): Eichenmischwald, V. MARKGRAF einzelner Taxa (1970a, 1972): Picea, S. WEGMÜLLER (1984): Buxus, M. WELTEN (1957): Ephedra, H. ZOLLER (1960b): Corylus, Eichenmischwald, Picea, Abies (1964): Abies; H. ZOLLER u. H. KLEIBER(1967): Fagus

Regionale C.BURGA (1982a, b): Graubünden, F. FIRBAS (1949/52): Mitteleuropa nördlich der Alpen, Vegetationsgeschichte M.-J. GAILLARD (1981, 1984): Moyen-Pays Romand, Lac Léman; R. HANTKE (1978-1983): gesamte Schweiz, A. HOFFMANN (1957): Glarner Alpen, P. KELLER (1930): Graubünden, (1934): Westschweiz; F. KRAL (1979): Alpen, W. LÜDI (1935b): Mittelland, V. MARKGRAF (1907b): Alpen, F. MATTHEY (1971): Jura central, C. REYNAUD (1983): Bassin genevois, R. SCHNEIDER (1985): Alpensüdrand, S. WEGMÜLLER (1966): Jura (1980): Seeland; M. WELTEN (1958): Berner Alpen, Wallis; (1972, 1982c): Nördliche Voralpen; (1979): Aaretal, H. ZOLLER (1960a): Südschweiz

Postglaziale C. BURGA (1979, 1980, 1987), H. J.BEUG (1982), H. ZOLLER $(1967,1977)$

Klimaschwankungen

ca. 1460 ha nur etwa $10-20 \%$ des ursprünglichen Bestandes entspricht, wovon nur ungefähr ein Drittel noch in naturnahem Zustand sich befindet. Die 489 festgestellten Moorobjekte verteilen sich heute sehr unregelmässig über die ganze Schweiz, wobei über $70 \%$ aller Hochmoore zwischen 850 und $1450 \mathrm{~m}$ ü. M. sich befinden, also im Bereich derVoralpen eine gewisse Häufung festzustellen ist.

Die Übersichtsarbeit von G. LANG (1985) über die pollenanalytische Forschung in der Schweiz von 1925-1985 zeigt eine relativ spärliche Anzahl von Standardprofilen für die Zeit von der Ältesten Dryas bis zum Subatlantikum. Dasselbe gilt auch für den Zeitpunkt Älteste Dryas/Bölling-Jüngere Dryas. Das Postglazial ist diesbezüglich erwartungsgemäß besser repräsentiert, jedoch nur in sehr unregelmäßiger räumlicher Verteilung.

\subsection{Die Vegetationsverhältnisse während der Ältesten Dryas und die Entwicklung des zentral- alpinen Waldgürtels der Schweiz seit der Späteiszeit}

Die Figur 10 zeigt die Verbreitung der späteiszeitlichen Artemisia-Chenopodiaceae-Juniperus-EphedraHelianthemum-Gramineae-Steppe während der Ältesten Dryas-Zeit (ca. 15000 bis 13000 Jahre BP). Dabei fällt besonders auf, daß sich praktisch alle Untersuchungsstellen innerhalb des Würmmaximums befinden, und zwar bis in Hochlagen der Zentralalpen. Nur die noch höher gelegenen Paßübergänge, wie Großer St. Bernhard, Simplon, Gotthard, Lukmanier, San Bernardino, Splügen, Maloja, Bernina, waren damals noch nicht eisfrei, da für die meisten Fälle dies pollenanalytisch sich nachweisen läßt (G. FURRER, M. MAISCH und C. BURGA 1984, C. BURGA 1987). Der Nachweis der Ältesten Dryas bis in die innersten Alpentäler legt den
Schluß nahe, daß der letzte Würm-Hochstand um $18000 \mathrm{BP}$ innerhalb von etwa 3000 Jahren bis auf die Größenordnung von Talgletschern sich verringern mußte. Dies bedeutet, daß zur Zeit um 18000 $\mathrm{BP}$ bereits Bedingungen des Eiszerfalls herrschen mußten (trockeneres Klima). Wie bereits 1980 B. FRENZEL erwähnte, ist die Phase der großen Inlandeismaßen sehr wahrscheinlich vor $18000 \mathrm{BP}$ zu legen. Auf ein rasches Schmelzen des würmeiszeitlichen Eisstromnetzes vor dem Bölling-Interstadial weisen auch die palynologischen Arbeiten in den französischen Alpen (J. L. BOREL. M. JORDA et G. MONJUVENT 1984). Schon vor dem Beginn des Bölling befanden sich demnach die Gletscher auf Meereshöhen von über $2100 \mathrm{~m}$ (in: Oisans/La Muzelle, Mercantour-Massiv/Lac Mouton)!

Vergleicht man die palynologisch rekonstruierte $\mathrm{Pa}$ läovegetation der Schweiz zur Zeit der Ältesten Dryas, so fällt die große Einförmigkeit auf. Es handelt sich durchwegs um Rohböden- bzw. Steppengesellschaften, die von Artemisia, Chenopodiaceae, Ephedra, Gypsophila, Saxifraga oppositifolia, Helianthemum, Thalictrum, vereinzelt von Juniperus und Betula nana, gebildet werden. M.WELTEN (1972) fand in der Pollenzone Ia in den Profilen Murifeld und Saanenmösern u. a. Achillea erba-rotta, A. atrata, Antennaria dioeca, Senecio spec., Herniaria glabra, Bellidiastrum michelii, Daucus carora, Scleranthus spec., Saxifraga stellaris, aber auch schon typische Wiesenpflanzen, wie Centaurea montana, $C$. scabiosa, Plantago alpina, P. media, Knautia spec., Linum cf. alpinum, und erste Anzeichen der Zwergstäucher (Arctostaphylos uva-ursi, Empetrum spec., Calluna vulgaris). Die Pollentetraden der letztgenannten Ericaceae finden sich vereinzelt in vielen späteiszeitlichen Profilabschnitten (vgl. C. BURGA 1980), wobei Calluna am häufigsten auftritt. Möglicherweise dokumentieren diese Sporomorphen eine spärliche eiszeitliche Nunatakkr-Vegetation. 
Lediglich am Alpensüdfuß (Italien) zeichnet sich ein etwas anderes Vegetationsbild während der Ältesten Dryas ab: Hier treten zu den bisherigen Steppenelementen vor allem Juniperus, Pinus und bereits früh Betula alba, Pinus cembra und stellenweise sogar Larix (R. SCHNEIDER 1978, 1985; Holzfund in Fornaci di Revine/Treviso, In: CASADORA et al. 1976, datiert um 14765 BP). Die bisherigen ältesten Radiocarbon-Alter im Bereich der Ältesten Dryas/ Bölling der verschiedenen Untersuchungsstellen weisen eine ähnliche Einförmigkeit auf. Dies sei an einigen Beispielen illustriert:

- Moyen-Pays Romand (Genferseegebiet): 13200 BP (M. J. GAILLARD1984)

- Murifeld/Bern: 13860 BP (M. WELTEN 1972)

- Nordschweiz (Nußbaumer Seen): 13100 BP (M. RÖSCH 1983)

- Berner Oberland (Amsoldinger See): 13490 BP (A. LOTTER 1985)

- Wallis (Hobschensee/Simplon): 12580 BP (M. WELTEN 1982b)

- Graubünden (Suossa-S. Bernardino): 13060 BP (H. ZOLLER 1971a)

- Südschweiz (Aurafreida/Puschlav): 14150 BP (C. BURGA 1987)

- Südalpen (Pian di Gembro/Aprica): 13490 BP (H. ZOLLER unpubl.)

- Alpensüdfuß (Biandronno/Varese): 13290 BP (R. SCHNEIDER 1978)

Vorliegende Alter liegen zwischen 13000 und 14000 $\mathrm{BP}$, obwohl viele der betreffenden Profile pollenanalytisch gesehen noch weiter zeitlich zurückreichen. Es ist unverständlich, weshalb an den tiefstgelegenen Lokalitäten des Mittellandes keine älteren Daten zum Hoch- und Spätwürm bisher zu erzielen waren. Dem allgemeinen Schema zum sukzessiven späteiszeitlichen Abschmelzen der Vorlandvereisung zufolge sollten in den höher gelegenen Alpentälern - ausgenommen Nunatak kr-Situationen - zunehmend jüngere Alter zu erwarten sein. Die bisherigen Radiocarbon-Daten bestätigen diese Modellvorstellung aber nicht. Einzig die Sedimente des Zürichsees (Grenze zur Würm-Grundmoräne) konnten mit einem ungefähren Alter von 15500 Jahre BP datiert werden (G. LISTER u. K. KELTS 1984).

Das bisher bekannte Vegetationsbild während der Ältesten Dryas dürfte aber kaum so einheitlich bzw. eintönig gewesen sein, wie man zunächst aus den vorliegenden Pollenanalysen schließen könnte. Nebst dem Problem der umgelagerten Palynomorphen (vgl. U. GRONER 1986) und der unterschiedlich guten Pollenerhaltung dürfte vor allem auch die Schwierigkeit, den Fern-, Regional- und Lokalpollenniederschlag voneinander zu unterscheiden, bei der pollenanalytischen Interpretation eine wichtige Rolle spielen. Bezüglich der Makroresten-Funde in der Pollenzone Ia zeichnen sich aber klare Unterschiede zwischen dem Mittelland und den Alpentälern ab, indem die ersten Großrestenfunde der alpinen Lokalitäten frühestens im Bölling auftreten (Betula alba. Pinus silvestris, vgl. (. BURGa 1980). Wie die ausgedehnten Untersuchungen von M.-J. GAILLARD und B. WEBER (1977, 1980, 1984) im Moyen-Pays Romand zeigen, treten bereits in Pollenzone Ia Makroresten von Betula alba. B. nana. Salix spec., Alnus spec., Potamogeton. Batrachium. Carex spec., Gypsophila repens u. a. auf. Auch die Sedimente des Lobsigensees (Berner Mittelland, к. TOBOLSK1 1983) lieferten in Pollenzone Ia auch reichlich Makroresten: Betula alba. B. nana. B. pubescens, B. tortuosa. Selaginella Selaginoides, Polygonum lapathifolium. Myriophyllum verticillatum. Chara spec.

Das vermutlich rasche Gletscherabschmelzen im Würm-Spätglazial ließ in relativ kurzer Zeit ein groBes Areal an Rohböden entstehen, so daß auf weite Strecken hinweg verschiedenartige Pioniergesellschaften Fuß fassen konnten. Gesamtschweizerisch eindeutig ist die auch sauerstoffisotopenanalytisch nachweisbare Erwärmung zu Beginn des Bölling-Interstadials (vgl. auch den Artikel von U. EICHER in diesem Heft). Zu diesem Zeitpunkt drangen Betula. Juniperus (wo nicht bereits früher vorhanden), Hippophaë und Pinus bis weit in die Alpentäler vor. Auch die Makrorestenfunde nehmen oft sprungartig zu.

Der weitere vegetationsgeschichtliche Verlauf seit dem Alleröd-Interstadial mit einer Wiederbewaldung durch Pinus, Pinus cembra (und Larix in den Südalpen) und Betula bis auf etwa $1600 \mathrm{~m}$ ü. M. ist in der Schweiz relativ gut bekannt.

Die Figur 11 zur Entwicklung des zentralalpinen Waldgürtels der Schweiz seit der Späteiszeit und der ungefähre Verlauf der klimatischen Schneegrenze soll das Zusammenspiel von Klima und Vegetation in Abhängigkeit von Zeit und Höhenlage zusammenfassend verdeutlichen.

Dieses Diagramm mit der Zeitachse als Abszisse und den Höhenmetern als Ordinate stellt die Entstehung und Veränderung vom Wald- und Steppengürtel, vom alpinen Gürtel und die Wandlung zu Kulturland dar. Ferner sind aus dieser Darstellung der generelle Anstieg von Wald- und Schneegrenze an der Wende von der Spät- zur Nacheiszeit und die darauffolgenden klimatisch und anthropogen bedingten Schwankungen sowie die Einwanderung und Ausbreitung der wichtigsten waldbildenden Holzarten ersichtlich.

Die nach dem letzten Würm-Maximum um 18000 oder 20000 Jahre BP einsetzende Klimaverbesserung kommt in den gemäßigten Breiten der NordHalbkugel durch ein rasches, bisweilen sogar plötzliches Abschmelzen der Gletscher um 15000 BP zum Ausdruck. Innerhalb von etwa 2000 Jahren stieg die Oberflächentemperatur des Atlantiks um 


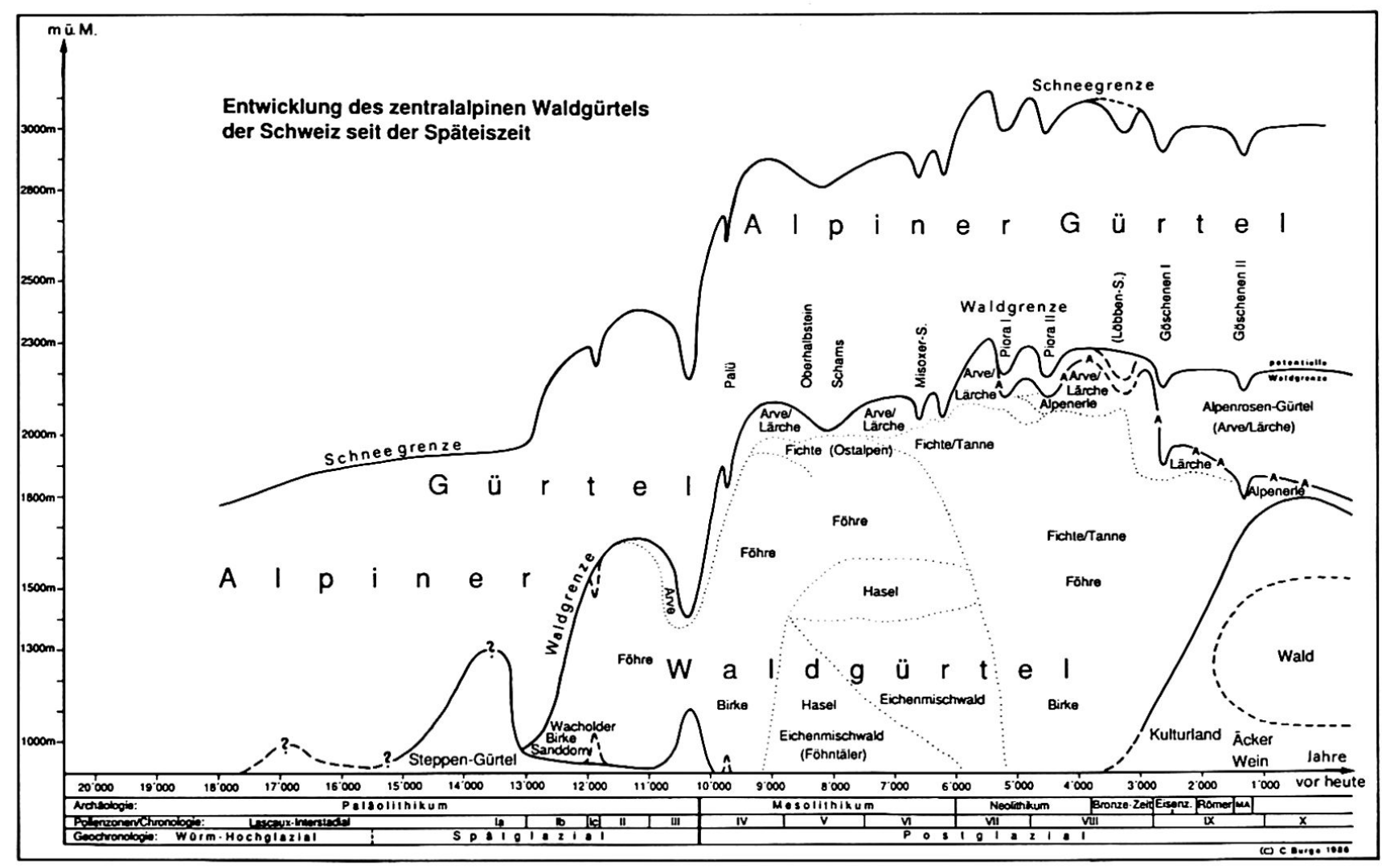

Fig. 11 Entwicklung des zentralalpinen Waldgürtels der Schweiz seit der Späteiszeit

Fig. 11 Development of the Central Alpine wood belt of Switzerland since the Würm Late-Glacial

etwa $14^{\circ} \mathrm{C}$ (Golf von Biskaya). In dieser Zeit konnte sich ein Steppengürtel, bestehend aus Wermut, Gänsefußgewächsen, Nelkengewächsen, Gräsern und Meerträubel, auf dem eisfrei gewordenen Areal herausbilden. Während dieser Periode des Eiszerfalls änderte sich ein Weltall-Element, nämlich das Perihel. Vor 12000 bis 8000 Jahren fiel es mit dem Sommer auf den Nord-Halbkugel zusammen und begünstigte so die Sommertemperaturen. Die extraterrestrische Sonnenstrahlung war damals um $7 \%$ höher.

Sollte diese Modellvorstellung richtig sein, so sind für die Südhalbkugel gerade die umgekehrten Verhältnisse bezüglich der Sommertemperaturen zu erwarten. Die neuesten paläoklimatischen Untersuchungen in Tasmanien von V. MARKGRAF (1986) scheinen dies zu bestätigen: Für die Zeit von 12000 bis $9500 \mathrm{BP}$ betrug das Jahresmittel $6^{\circ} \mathrm{C}$, und das Klima war besonders zwischen 10200 und $9500 \mathrm{BP}$ deutlich feuchter und kühler als heute.

Im Bölling-Interstadial wurden viele Standorte durch die aufkommenden Sträucher, wie Wacholder. Sanddorn, Zwergweiden, und die Birke besetzt. Dies ist die Reaktion auf die um 13000 BP einsetzende starke globale Erwärmung. Die Wald- und Schneegrenze bewegten sich rasch in Höhen um 1500 bzw. $2300 \mathrm{~m}$ ü. M. Die diesbezügliche erste Kulmination wurde im Alleröd-Interstadial um 11700 BP erreicht, wobei die späteiszeitliche Wiederbewaldung durch Föhre und Birke bis auf über $1600 \mathrm{~m}$ erfolgte. Auf Grund von Käferfaunen schloß G. R. COOPE (1977) auf eine Erhöhung der Sommertemperatur um 10 bis $12^{\circ} \mathrm{C}$ (in weniger als $100 \mathrm{Jah}$ ren). Der markante Klimarückschlag der Jüngeren Dryas, welcher sogar in Süd-Frankreich und Florida Vegetationsveränderungen bewirkte, zeichnet sich im ganzen Alpenraum durch eine Waldgrenzsenkung von 200 bis $300 \mathrm{~m}$ ab. Der vorher stark eingeengte Steppengürtel erfuhr nochmals eine Reaktivierung, bevor er in der Nacheiszeit auf Spezialstandorte verdrängt wurde. Polares Wasser drang noch bis zum Golf von Biskaya vor, und das Schottische Hochland wurde erneut vergletschert. Die Wende zur Nacheiszeit ist gekennzeichnet durch einen steilen Anstieg der Wald- und Schneegrenze auf 2100 bzw. $2900 \mathrm{~m}$ ü. M. Die im Alleröd eingewanderte Arve bildete nun im Präboreal zusammen mit der Lärche die Waldgrenze. Dieser Lärchen-ArvenGürtel erfuhr im Lauf des Boreals eine klare Einengung als Folge des damaligen Klimarückschlags. Zu 
Beginn des Älteren Atlantikums erreichte die von E nach W wandernde Fichte die Bündner Zentralalpen. Wenig später sind eine maximal hohe Waldgrenze in durchschnittlich $2300 \mathrm{~m}$ und eine klimatische Schneegrenze bis über $3100 \mathrm{~m}$ als Ausdruck des nacheiszeitlichen Klimaoptimums festzustellen.

Im Jüngeren Atlantikum und am Übergang zum Subboreal sind wieder klare Anzeichen zu Klimaverschlechterungen vorhanden, die um 5000 bis 4500 BP weltweit zu beträchtlichem Gletscherwachstum führten.

Seit dem ausgehenden Neolithikum ist an vielen Stellen der Zentralalpen die erste menschliche Rodungstätigkeit festzustellen. Diese zunächst mehr punktuellen Waldgrenz-Senkungen verstärkten sich seit der Eisen- und Römerzeit und besonders seit dem Frühmittelalter zu Waldgrenz-Depressionen von rund $300 \mathrm{~m}$. Die Klimarückschläge der Eisenzeit und des Frühmittelalters übten auf diese Waldgrenzsenkungen einen zusätzlichen verstärkenden Effekt aus. Der Waldgürtel wurde nun von unten und von oben her eingeengt. Die unteren Regionen lieferten nach der Rodung wertvolles Kulturland, während die alpwirtschaftlich genutzte Waldgrenz-Zone zu einer starken Einengung des Lärchen-Arven-Gürtels, stellenweise sogar zur völligen Zerstörung desselben führte. An dessen Stelle entwickelten sich meistens ausgedehnte Alpenrosen-Zwergsträucher-Bestände.

Fragen wir zum Schluß noch kurz nach der praktischen Bedeutung der Erforschung von Vegetationsund Klimageschichte, so treten zwei Hauptaspekte hervor, nämlich die Entwicklung unseres Klimas in der Zukunft und das damit zusammenhängende $\mathrm{CO}_{2}$-Problem und andererseits der anthropogen bedingte Landschaftswandel.

Hier seien nur kurz zum zweiten Punkt einige Bemerkungen hinzugefügt. Die pollenanalytische Untersuchung geeigneter Sedimente liefert Grundlagenkenntnisse für Natur- und Landschaftsschutzgebiete. Sie kann anthropogene Veränderungen des Naturhaushaltes aufdecken. Ferner gestattet sie die zeitliche Einstufung bwz. Abfolge wichtiger landschaftsverändernder Vorgänge, wie Uferzerstörungen, Änderungen des Wasserhaushaltes und Veränderungen der Standortfaktoren, zu ermitteln.

Die Erforschung des Paläoklimas mit Hilfe der Vegetationsgeschichte weist noch viele ungelöste Probleme auf, die hier nur kurz angedeutet seien. So können gewisse Klimaschwankungen heute noch zu wenig genau zeitlich abgegrenzt werden. Es geht also um die exaktere chronologische Einstufung des Datenmaterials in eine universelle Zeitskala, die bis etwa 125000 Jahre v. h. zurückreichen sollte.

Ferner gilt es, das Ausmaß einer Phase schlechteren Klimas zu ermitteln. Schließlich muß man bestrebt sein, die Vegetationsgeschichte und Paläoklimatologie über größere Gebiete zu rekonstruieren.

\section{Postglaziale Schwankungen der geomorphologischen Aktivität in den Alpen (M. Gamper)}

Bei der Rekonstruktion des Klimaverlaufs der Nacheiszeit sind wir auf indirekte Daten angewiesen. Die klimageschichtliche Information kann nur auf Umwegen gewonnen werden, weil aus diesem Zeitraum keine Temperatur- und Niederschlagsmessungen vorliegen. Unter der geomorphologischen Aktivität, einem indirekten Klimazeiger, verstehen wir beispielsweise die Bildung von Moränenwällen durch vorstoßende Gletscher, die Ablagerung von Verwitterungsschutt in Schwemmkegeln und Schutthalden oder die Entstehung von Solifluktionszungen. Die Lockergesteine, die dabei entstehen, wie Moränen, Frostschutt und Schotter, sind Zeugen einer Phase hoher geomorphologischer Aktivität. Bodenbildungen auf derartigen Lockergesteinen zeigen dagegen Unterbrüche der Sedimentation, also Ruhephasen der geomorphologischen Aktivität, an. Diese Wechsel von Aktivität und Stabilität, wie wir sie häufig in verschiedensten Akkumulationsformen in den Alpen finden, sind die Folge von Änderungen des Klimas. Die klimageschichtliche Information, die in Wechsellagerungen von Lockergesteinen und Bodenbildungen gespeichert ist, kann unter zwei Voraussetzungen genutzt werden: Die Information muß datierbar sein. Diese Bedingung ist mit der Radiokarbondatierung von organischem Material in fossilen, d. h. überschütteten Bodenbildungen erfüllt. Wir kennen dann - vereinfacht ausgedrückt - den Zeitpunkt des Abschlusses einer Bodenbildungsphase, also den Zeitpunkt des Wechsels von geomorphologischer Stabilität zu geomorphologischer Aktivität.

Die zweite Bedingung, die für eine klimageschichtliche Auswertung unsererWechsellagerungen erfüllt sein muß, ist die genaue Kenntnis der klimatischen Steuerung der geomorphologischen Prozesse.

Die bisherigen Untersuchungen (z. B. G. FURRER. F. BACHMANN Und P. FITZE 1971, F. RÖTHLISBERGER 1976, W. SCHNEEBELI 1976, F. BEELER 1977, M. GAMPER und J. SUTER 1982, M. GAMPER 1981 und 1985) konzentrieren sich auf vier geomorphologische Prozesse und deren korrelate Ablagerungen: Moränen, Schutthalden, Schwemmkegel und Solifluktionszungen.

Vorstöße von Gletschern sind in der Regel das Resultat einer längeren, überregionalen Phase der Klimaverschlechterung. Dabei kann ein Boden, der sich bei günstigem Klima im Gletschervorfeld oder auf den Seitenmoränen gebildet hat, mit frischem Moränenmaterial überdeckt und fossiliert werden. In einer Phase der Klimaverbesserung wird der Gletscher wieder abschmelzen, und es kann erneut zu einer Bodenbildung kommen. Eine Wechsellagerung von Moränenmaterial und fossiler Bodenbildung ist somit ein Zeuge für die Schwankungen ei- 
ner Gletscherzunge und damit auch fürVeränderungen des Klimas.

Aktivitäts- und Stabilitätsphasen können auch in Schutthalden nachgewiesen werden (D. HARTMANNBRENNER 1973: M. GAMPER 1985). Die klimageschichtliche Information einer'Wechsellagerung von Schutt und Bodenbildungen ist aber nicht dieselbe wie bei einem Gletschervorstoß, wird doch die Schuttproduktion in einer Schutthalde durch die Frostwechsel-Intensität gesteuert und nicht beispielsweise durch Änderungen der Sommertemperaturen, welche eine wichtige Ursache für Gletscherschwankungen darstellen.

Die klimatische Steuerung von Änderungen der Akkumulationsrate in Schwemmkegeln ist schwierig zu interpretieren. Im Gegensatz zu Gletschervorstößen oder Aktivitätsänderungen von Schutthalden, wo wir als Voraussetzung eine längerdauernde. überregionale Klimaveränderung annehmen können, ist eine Überschüttung eines Schwemmkegels durch neuen Schutt unter Umständen das Resultat eines einzigen Sommergewitters, das sich im Einzugsgebiet des Schwemmkegels entladen hat. Hinweise auf Klimaänderungen ergeben sich nur, wenn in bestimmten Zeitabschnitten der Nacheiszeit Häufungen von solchen Ereignissen festgestellt werden können (M. GAMPER 1985).

Bei den Akkumulationsformen, die durch den vierten und letzten hier betrachteten geomorphologischen Prozeß entstehen, handelt es sich um Erdströme. Diese zungenförmigen Gebilde von 10 bis $30 \mathrm{~m}$ Länge, $10 \mathrm{~m}$ Breite und etwa einem halben Meter Mächtigkeit sind das Resultat des langsamen Hangabwärtsfließens von Frostschutt, der sogenannten Solifluktion. Die Solifluktionszungen überfahren die vor ihnen liegende Bodenbildung. Wenn wir eine solche Zunge der Länge nach aufgraben, so finden wir häufig folgendes Bild: An der Erdoberfläche, auf dem Rücken der Solifluktionszunge erkennt man die etwa $10 \mathrm{~cm}$ mächtige, heutige Bodenbildung. Dieser $A_{h}$-Horizont ist ein Indiz dafür, daß sich diese Zunge nicht mehr bewegt. An der Basis des Erdstroms findet man einen zweiten derartigen Horizont. Es handelt sich dabei um eine fossile Bodenbildung, die während einer Aktivitätsphase durch diesen Erdstrom überfahren wurde.

Wenn wir nun diesen fossilen Boden mit Hilfe der Radiokarbonmethode datieren, erhalten wir ein $\mathrm{Al}$ ter, das uns den Abschluß dieser Bodenbildungsphase angibt, das heißt den Zeitpunkt der Überschüttung dieses Bodens durch Solifluktionsschutt (vgl. M. GAMPER und H. OBERHÄNSLI 1982; M. GAMPER 1985). Der Grad der Bodenentwicklung zeigt zusätzlich noch, ob die Phase geomorphologischer Stabilität, die Phase also, in der sich dieser Boden bilden konnte, einige Jahrhunderte, wenn nicht Jahrtausende angedauert hat.

Was können wir nun über Zeiträume hoher solifluidaler Aktivität klimageschichtlich aussagen? Wir wissen von den Untersuchungen über die klimatische Steuerung der Solifluktion im Schweizerischen Nationalpark (M. GAMPER 1981, 1983), daß große Solifluktionsbeträge dann auftreten, wenn die Winter schneearm und kalt sind. In diesen Zeiträumen müssen deshalb kalte und schneearme Winter wesentlich häufiger vorgekommen sein als heute. Aufgrund dieser Messungen muß angenommen werden, da $\beta$ in solchen Zeiten die mittlere Dauer der Winterschneedecke etwa 30 Tage kürzer war als heute und daß die mittleren Wintertemperaturen mindestens $1 \mathrm{Grad}$ tiefer lagen.

Geringe geomorphologische Aktivität, das heißt Zeitabschnitte, in denen keine Solifluktionszungen vorgestoßen sind, deuten dagegen auf Phasen mit schneereichen und milden Wintern. Etwas verallgemeinert heißt das, daß Zeiträume mit geomorphologischer Aktivität in Form von erhöhter Solifluktion auf ein eher kontinentales Klima hinweisen, Zeiträume geomorphologischer Stabilität, die Bodenbildungsphasen, sind dagegen als Phasen mit eher ozeanischem Klima zu verstehen. Diese allgemeinen Aussagen sind natürlich für bestimmte Zeitabschnitte der Nacheiszeit erst gesichert, wenn identische Phasen nicht nur an einzelnen Orten nachgewiesen werden können, sondern an möglichst vielen verschiedenen Lokalitäten in den Alpen.

Was wissen wir nun heute bereits über Schwankungen der geomorphologischen Aktivität in den Alpen während der Nacheiszeit? Bisher sind $275{ }^{{ }^{H}} \mathrm{C}$-Alter von fossilen Bodenbildungen unter Solifluktionszungen, Moränen sowie unter Ablagerungen von Schwemmkegeln und Schutthalden bestimmt worden (Fig. 12). Die in M. GAMPER (1985) vorgestellte statistische Auswertung der ${ }^{\mathrm{H}} \mathrm{C}$-Daten ermöglicht es uns, einen ersten Überblick über die Schwankungen der geomorphologischen Aktivität in den Schweizer-Alpen während der Nacheiszeit zu erhalten. Ein Problem, das dabei berücksichtigt werden muß, ist die Abweichung der Radiokarbonzeitskala von der Kalenderzeitskala (vgl. M. GEYH 1983). Deshalb zuerst einige Bemerkungen zur Verteilung links in der Fig. 12. Diese theoretische Verteilung ergibt sich, wenn in jedes Jahrhundert der Kalenderzeitskala gleich viele ${ }^{{ }^{+} \mathrm{C}} \mathrm{C}$-Daten fallen würden, $\mathrm{d}$. h. also, wenn gar keine Häufungen von Überschüttungen von Bodenbildungen vorkommen, sondern wenn solche Ereignisse während der ganzen letzten 6000 Jahre immer etwa gleich häufig auftreten. Echte Maxima und Minima sind in den drei Datenverteilungen nur dort anzunehmen, wo sie nicht mit vorgetäuschten Maxima und Minima in der theoretischen Verteilung zusammenfallen. Bei dem gewählten Klassenintervall von 250 Radiokarbonjahren ist diese Gefahr von vorgetäuschten Schwankungen aber offensichtlich nur gering. Die Verteilung ist sehr ausgeglichen.

Nun zu den eigentlichen Daten. Häufungen von Daten entsprechen Zeiträumen, in denen besonders 
Anzah1 14C-Daten
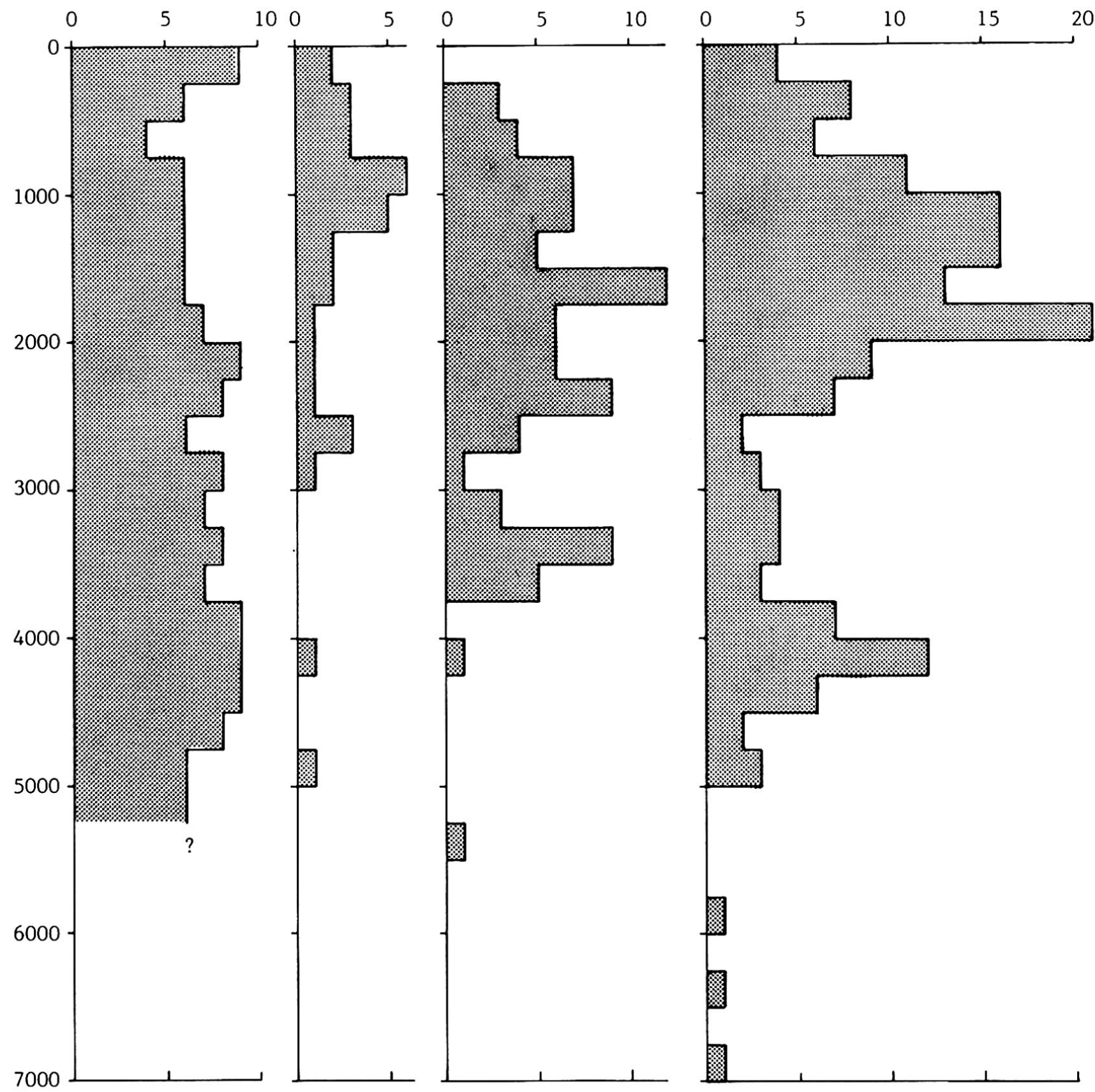

Jahre

BP

Theoretische Verteilung von 150 gleichmässig auf den Zeitraum 2000 n.Chr. bis 4000 v.Chr. ver-

teilten Daten

Schwemmkege1 Gletscherschwankungen: Solifluktionsphasen: und Schutt- 83 14C-Daten 160 14C-Daten

halden:

32 14C-Daten

Fig. 12 Häufigkeitsverteilung der ${ }^{14} \mathrm{C}$-Daten über Schwankungen der geomorphologischen Aktivität in den Schweizer Alpen. Die Klassenbreite beträgt 250 Jahre (aus M. Gamper 1985, Abb. 37)

Fig. 12 Radiocarbon dates and fluctuations of geomorphological activity in the Swiss Alps. Range of the classes: 250 years (after M. Gamper 1985, fig. 37) 
viele Bodenbildungen überschüttet und fossilisiert wurden. Die Maxima der Kurven zeigen also Phasen großer geomorphologischer Aktivität an. Auffallend ist bei allen drei Histogrammen, daß die meisten Daten im Zeitraum von 4500 Jahren vor heute bis heute liegen. Nur vereinzelte Daten fallen in die erste Hälfte der Nacheiszeit, das heißt in den Zeitraum von 7000 bis 4500 vor heute. Aufgrund dieser Verteilung der ${ }^{{ }^{H}} \mathrm{C}$-Daten vermute ich, daß die geomorphologische Aktivität in den Alpen im Klimaoptimum in der ersten Hälfte der Nacheiszeit sehr gering war. Die zweite Hälfte der Nacheiszeit, ab etwa 4500 Jahren vor heute, ist aufgrund des Kurvenverlaufes der Histogramme gekennzeichnet durch kurzfristigere Wechsel von Phasen der geomorphologischen Aktivität und kurzen Phasen der geomorphologischen Stabilität mit Bodenbildung. D. h., nach dem Klimaoptimum der Nacheiszeit mit vorherrschend ozeanisch geprägtem Klima ist die zweite Hälfte der Nacheiszeit geprägt durch häufige Wechsel von Zeitabschnitten mit eher kontinentalem und Zeitabschnitten mit ozeanischem Klima.

In Zukunft scheint es mir notwendig, daß die Datenbasis, das heißt die Anzahl ${ }^{{ }^{+}} \mathrm{C}$-Altersbestimmungen von fossilen Bodenbildungen, noch stark erweitert wird. Dies würde auch eine unbedingt notwendige regionale Gliederung der Befunde erlauben, z. B. Nordabdachung und Südabdachung der Alpen. Im weitern sind die prozeßorientierten Untersuchungen an Solifluktionszungen fortzusetzen, denn Meßreihen von nur 10 Jahren, wie sie aus dem Schweizerischen Nationalpark heute vorliegen, sind zu kurz, um eine abschließende Beurteilung über die klimatische Steuerung dieses Prozesses zu gestatten. Andere geomorphologische Prozesse, wie die Frostsprengung und die fluviatile Aktivität in den Alpen, um nur zwei Beispiele zu nennen, müssen in Zukunft ebenfalls noch auf ihre klimatische Steuerung hin untersucht werden.

\section{Betrachtungen zur Gletschergeschichte des Postglazials}

(H. Holzhauser)

\subsection{Einleitung}

Zur Erforschung von postglazialen Klimaschwankungen werden bekanntlich verschiedene Wege beschritten. Eine Möglichkeit ist die Rekonstruktion von Gletscherschwankungen, denn Gletscherbewegungen sind, von wenigen Ausnahmen abgesehen, erwiesenermaßen klimagesteuert.

Zum Thema «Postglaziale Schwankungen der Alpengletscher» sind bereits mehrere Diplomarbeiten und Dissertationen erschienen. Für nähere Angaben sei auf die Publikationen von fURrer et al. (1978), RÖTHLISBERGER F. et al. (1980) und GAMPER \& SUTER (1982) verwiesen. Eine dem jeweiligen Forschungsstand entsprechende Zusammenstellung aller gletschergeschichtlich relevanten Radiokarbondaten ist den genannten Arbeiten ebenfalls zu entnehmen.

In jüngster Zeit wurde der Forschungszweig «Postglaziale Gletschergeschichte» durch weitere Arbeiten bereichert. Bereits nachgewiesene Gletschervorstöße konnten bestätigt werden, und im Bereich des Mittelalters gelang es zudem, das Ausmaß einzelner Vorstoßphasen genauer zu erfassen.

Neuere, bereits erschienene oder in Vorbereitung sich befindende Veröffentlichungen seien an dieser Stelle kurz erwähnt:

Die Rekonstruktion der Gletscherschwankungen im Mont Blanc-Gebiet ist Gegenstand der Dissertationen von AESCHLIMANN (1983), BLESS (1984) und WETTER (1987). Eine umfassende Bearbeitung des reichlich vorhandenen Bildmaterials von Gletschern aus dem Raum Chamonix wird momentan von ZUMBÜHL durchgeführt. Im Wallis sind gletschergeschichtliche Untersuchungen am Großen Aletsch- und Fieschergletscher (HOLZHAUSER 1984), am Ried- und Zinalgletscher (HOLZHAUSER 1985), am Gornergletscher (BLEULER 1986) und am Langgletscher (MEIER 1986) durchgeführt worden. Im weiteren wurden zwei Diplomarbeiten am Glacier de Ferpècle, am Glacier d'Arolla und am Glacier de Saleina angesetzt. Neben der Gletschergeschichte sind auch dendrochronologische Analysen miteinbezogen. In Vorbereitung ist eine größere Publikation über die Schwankungen des Rhone-, des Unteraar-, des Rosenlaui- und des Unteren Grindelwaldgletschers (ZUMBÜHL \& HOLZHAUSER, erscheint 1988). Gorner- und Belvederegletscher werden in einer kleineren Publikation abgehandelt (HOLZHAUSER in Vorber.). Im kürzlich erschienenen umfangreichen Werk «10000 Jahre Gletschergeschichte der Erde" untersuchte RÖTHLISBERGER F. (1986) weltweit Gletscherschwankungen. Im Laufe mehrerer Expeditionen sind zahlreiche fossile Böden und Hölzer geborgen und anschließend mit der Radiokarbonmethode datiert worden. Die regionale Zusammenfassung der Daten zu Kurven der Gletscherschwankungen erlaubte dann dem Autor, sich an einen Vergleich Nord-/Südhemisphäre bezüglich Gletscher- und Klimaschwankungen heranzuwagen.

Eine kritische Sichtung und Wertung der reichlich vorhandenen ${ }^{1+} \mathrm{C}$-Daten aus dem Alpenraum ist Ziel einer laufenden Untersuchung. Bestandteil dieser Arbeit ist der Aufbau einer Datenbank.

Aufgrund bestehender Kurven der postglazialen Gletscherschwankungen kann leicht der Eindruck entstehen, daß sämtliche nachgewiesene Vorstoßund Rückschmelzphasen der letzten 10000 Jahre 
ähnlich gut belegt und abgesichert sind. In Wirklichkeit bestehen große Unsicherheiten, die ihre Ursachen in der unterschiedlichen Aussagekraft der Daten haben. Es scheint mir deshalb wichtig, einige grundsätzliche Überlegungen, die bei der Interpretation von gletschergeschichtlichen Daten berücksichtigt werden sollten, kurz zu umreißen.

\subsection{Methoden: Aussage und Grenzen}

Über Methoden, die zur Rekonstruktion von postglazialen Gletscherschwankungen beigezogen werden, ist schon verschiedentlich geschrieben worden. Eine ausführliche Behandlung dieses Themenkreises wird deshalb nicht angestrebt; vielmehr soll zeitliche Reichweite, Aussagekraft und zeitliches Auflösungsvermögen kurz in Erinnerung gerufen werden.

Quellen, aus denen gletschergeschichtliche Information geschöpft wird, lassen sich wie folgt gruppieren:

- Auswerten von historischen Schrift- und Bildquellen

- Auswerten von anthropogenen Spuren im Gelände (Geländearchäologie), die in Zusammenhang mit Gletscherbewegungen oder lokalen Vereisungen, z. B. bei Pässen, gebracht werden können (alte Wege, Wasserleitungen, Wüstungen).

- Eigentliche Feldmethoden: Das Bergen und Datieren von überschütteten Böden und fossilen Bäumen aus dem Gletschervorfeld.

Da historisches, gletschergeschichtlich auswertbares Quellenmaterial lediglich aus einigen Jahrhunderten zur Verfügung steht, ist diese Methode auf den Zeitraum der Neuzeit - der letzten rund 450 Jahre - beschränkt. Aus dem Spätmittelalter sind nur wenige, isoliert auftretende Informationsfragmente greifbar. Das Auswerten von Bilddokumenten setzt fundierte kunsthistorische Kenntnisse voraus, wie dies die Arbeit von ZUMBÜHL (1980) zeigt. Das zeitliche Auflösungsvermögen reicht von Jahrzehnten bis zu einem Jahr und ist einerseits abhängig von der Informationsdichte und andererseits von der Qualität der Bilder und Aufzeichnungen.

Oft liegen Hinweise geländearchäologischer Art vor, auch aus der Vorneuzeit (vor 1500 A. D. ). Sie sind allerdings nur dort aussagekräftig, wo sie mit schriftlichem Quellenmaterial kombiniert und untermauert werden können; allzuviel Spielraum bleibt sonst für Spekulationen offen. Nur in den wenigsten Fällen sind jahrgenaue Datierungen möglich, wie das zum Beispiel bei Zerstörungen von Behausungen durch einen Gletscher oder bei Wasserleitungen der Fall ist. Häufig erschöpft sich die Datierung in einer weitgefaßten Zeitmarke wie «neuzeitlich», «mittelalterlich» oder «römisch».

Gletschervorstöße im Postglazial außerhalb des Spätmittelalter-/Neuzeitbereichs - dieser Zeitraum umfaßt immerhin rund 9300 Jahre - sind nur deshalb zeitlich faßbar, weil wir mit der Radiokarbonmethode das Alter vom Gletscher überschütteter Böden und überfahrener Hölzer bestimmen können. Mit Hilfe der Dendrochronologie kann zudem in günstigen Fällen das Absterbealter von fossilen Hölzern in Kalenderjahren angegeben werden. In der überwiegenden Zahl der Fälle bleibt die Radiokarbondatierung alleinige Altersbestimmungsmethode. Nach GEYH (1986: 322) lassen sich auf diese Weise Gletschervorstöße nicht präziser als auf \pm 150 bis \pm 200 Jahre genau bestimmen. Dies entspricht einem zeitlichen Auflösungsvermögen von 300 bis 400 Jahren.

\subsubsection{Fossile Böden}

Stratigraphisch lassen sich zwei Arten fossiler Böden unterscheiden (Fig. 13):

Im ersten Fall handelt es sich um Böden, die am Rande des Gletschervorfeldes auftreten. Einerseits findet man sie als dunkle, voneinander durch Moränenschutt getrennte Horizonte im anerodierten Teil der steil abfallenden Ufermoränen; andererseits liegen fossile Böden unter angelagerten Ufer- und Endmoränen verborgen (s. dazu SCHNEEBELI 1976 und RÖTHLISBERGER F. 1976, 1986). Der zweite Fall schließt Böden ein, die flächenhaft im Innern des Vorfeldes entweder natürlich oder künstlich aufgeschlossen sind. Sie treten sowohl im flacheren Abschnitt des Vorfeldes als auch an der gletscherwärtigen Seite der Ufermoränen auf.

Die Unterscheidung in diese zwei Gruppen ist zwingend: Im ersten Fall werden Gletscherhochstände

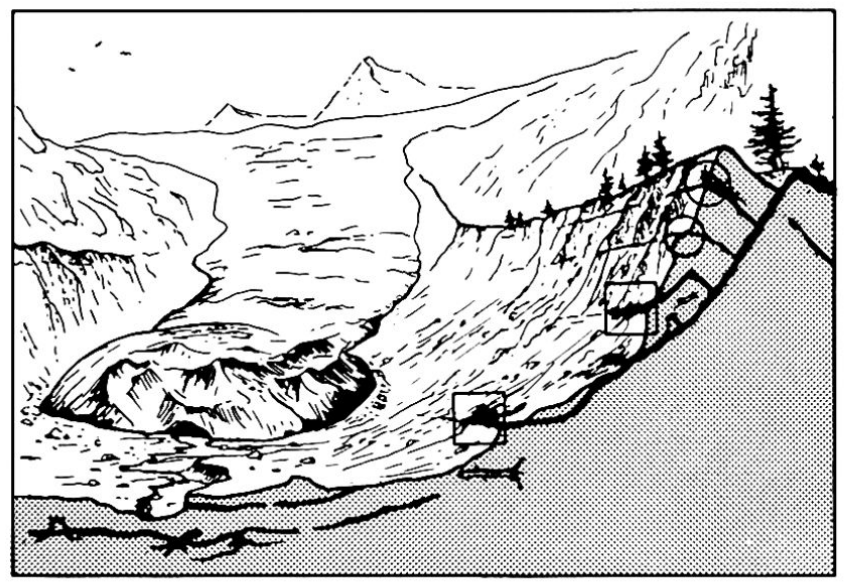

Fig. 13 Lage fossiler Böden in einem Gletschervorfeld

Hochstand belegt

Mindestausdehnung belegt

Fig. 13 Fossil soils in a "gletschervorfeld"

$\bigcirc$ Evidence for a maximum extension

$\square$ Evidence for a minimum extension 
nachgewiesen; der Gletscher erreichte jeweils bezogen auf die Vorfelddimension maximale Ausdehnung. Im anderen Fall bestimmt die Lage des Fundortes die Mindestausdehnung der Gletscherzunge zum Zeitpunkt der Überschüttung; wie weit der Gletscher nachträglich darüber hinaus vorgestoßen ist, bleibt hingegen ungewiß. Je geringer die Entfernung des Fundortes zum aktuellen Gletscherrand ist, desto geringer war die Gletscherausdehnung vor Beginn der Klimaverschlechterung.

Die Alter von übereinanderliegenden Böden in einem ungestörten Moränenprofil belegen aufgrund ihrer stratigraphischen Lage eindeutig verschiedene Vorstoßphasen. Auch zeitlich nahe beieinanderliegende ${ }^{H} \mathrm{C}$-Daten können in diesem Falle getrennt werden. BIRCHER (1982: 84) wies zum Beispiel Vorstöße des Allalingletschers aufgrund zweier übereinanderliegender Böden nach, nämlich um 3440 \pm 125 yBP und um $3270 \pm 135$ yBP. Würde es sich jedoch um Böden aus zwei verschiedenen Vorfeldern handeln, wäre diese Trennung nicht erlaubt, weil die 14C-Daten sich im $1 \sigma$-Bereich überschneiden und folglich statistisch nicht unterscheidbar sind.

Ein grundsätzliches Problem stellt sich im Zusammenhang mit fossilen Böden in Ufermoränen. Wie SCHNEEBELI (1976) und RÖTHLISBERGER F. (1976) feststellten, kann der horizontweise Aufbau einer Ufermoräne - Moränenschutt/fossiler Boden/Moränenschutt/fossiler Boden/etc. - Folge einer Gletscherbetterhöhung nach jeder Vorstoßphase sein. Die zwischen zwei Böden eingeschalteten Moränenpakete dokumentieren somit Gletschervorstöße gleichen Ausmaßes, was die Eismächtigkeit an der Profilstelle anbelangt. Länge und Breite des Gletschers hingegen müssen nicht zwangsläufig immer gleich gewesen sein. Bei einigen Gletschern erfolgte offenbar keine Erhöhung des Gletscherbettes (Glacier d'Argentière, BLESS 1984); trotzdem fanden aber mit fossilen Böden belegbare Überschüttungen der Ufermoränen statt. Auf den ersten Blick deutet eine solche Situation darauf hin, daß jeder Gletschervorsto $\beta$ den vorangegangenen im Ausmaß übertroffen hat und deshalb die auslösende(n) Klimaverschlechterung(en) entsprechend an Intensität zugenommen hat bzw. haben. Im Moränenprofil des Glacier d'Argentière datiert der unterste Boden (etwa 15 m über der Eisoberfläche von 1981) aus der Zeit' um 3600 yBP, der oberste Boden wurde während der Neuzeit überschüttet. RÖTHLISBERGER F. (1986: 66) deutet dies als Hinweis für einen fallenden Temperaturtrend seit rund 3500 Jahren. Demzufolge wäre der neuzeitliche Hochstand vom klimatischen Standpunkt aus betrachtet der intensivste gewesen, was aber nachweislich nicht der Fall ist. In den Alpen sind nämlich Hochstände in der Zeit nach 3500 vor heute belegt, die im Ausmaß den neuzeitlichen ebenbürtig waren und diese zum Teil gar übertroffen haben (RENNER 1982, HOLZHAUSER 1984). Die Ursache für Fälle wie Argentière, so scheint mir, ist eher im Relief, im komplexen Aufbau der Ufermoränen sowie im Wechselspiel zwischen Aufschüttung und Erosion (Gletscherbettverengung/Gletscherbetterweiterung) und der daraus resultierenden veränderten Gletscherform bei jedem Vorstoß begründet als in übergeordneten Klimatrends.

\subsubsection{Fossile Hölzer}

Bedingt durch den Gletscherschwund seit 1850 und dem damit verbundenen Eisfreiwerden großer Teile der Gletschervorfelder mehren sich Funde von Resten einstmals vom Gletscher überfahrener Bäume. Auf die Auswertung solcher Holzfunde wird in einigen Publikationen jüngeren Datums näher eingegangen (RÖTHLISBERGER F. 1976, FURRER \& HOLZHAUSER 1984, HOLZHAUSER 1984, RÖTHLISBERGER F. 1986). Deshalb sei hier nur kurz das Wichtigste festgehalten:

Mit der Radiokarbonmethode, in einigen Fällen auch auf dendrochronologischem Wege, ist das Absterbealter eines Baumes bestimmbar, und damit kann auch die zeitliche Stellung des Gletschervorstoßes festgelegt werden. Das Auszählen der Jahrringe ermöglicht das Abgrenzen eines Mindestzeitraumes, während dem der Fundort eisfrei war. Auch hier gilt, wie für fossile Böden innerhalb des Vorfeldes: Je näher der Fund am aktuellen Eisrand liegt, desto weiter kann die Ausgangsposition eines Gletschers vor dem betreffenden Vorstoß «zurückgedrängt" werden.

Es versteht sich von selbst, daß für gesicherte Aussagen nur fossile Bäume in Frage kommen, die in situ (d. h. am Fundort gewachsen) sind. Bei der Interpretation von Streufunden - an der Oberfläche liegende sowie aus der Grundmoräne ausgeschwemmte oder gegrabene Hölzer - ist Vorsicht geboten. Eine gletschergeschichtliche Auswertung ist nur dann sinnvoll und zulässig, wenn die Funde im Zusammenhang stehen mit gleichaltrigen Böden oder Holzfunden in situ.

Mehrere gleichaltrige Baumreste aus verschiedenen Bereichen des Gletschervorfeldes sind aussagekräftiger als nur der Einzelfund. Das Postulieren eines Gletschervorstoßes aufgrund eines einzigen fossilen Holzes ist deshalb problematisch, weil durch Erdrutsch und Lawinen ein Baum ebenfalls absterben kann.

\subsection{Klimageschichtliche Interpretation von Gletscherkurven}

Die Reaktion eines Gletschers auf Klimaänderungen ist verzögert. Das Verhalten eines Gletschers - 
vorstoßend, abschmelzend oder stationär - widerspiegelt je nach Größe Witterungsverhältnisse, die Jahre oder Jahrzehnte zurückliegen. «Gletscherkurven" sind deshalb gegenüber "Klimakurven" verschoben; Gletschervorstöße beispielsweise hinken Klimaverschlechterungen nach. Die Verzögerungszeit ist gletscherindividuell verschieden und reicht von einem Jahr für kleine bis Jahrzehnte für große Gletscher (GAMPER \& SUTER 1978). Die Verschiebung der beiden Kurven ist allerdings nur dort erkennbar und zahlenmäßig in Jahren faßbar, wo der Beginn sowohl der Klimaverschlechterung als auch des anschließenden Gletschervorstoßes in Kalenderjahren bekannt ist, also hauptsächlich im Bereich der Neuzeit. Der Fehlerbereich der ${ }^{{ }^{+}} \mathrm{C}$-Daten ist zu groß, um Verzögerungszeiten auch in früheren Abschnitten des Postglazials feststellen zu können.

Aus historischen Quellen gewonnene und natürliche Daten (z. B. ${ }^{1+}$ C-Daten) bilden die Grundlage für die zeichnerische Rekonstruktion der Gletscherschwankungen in Form einer Kurve. Von den wenigsten Gletschern sind jedoch die erforderliche Datendichte und -qualität vorhanden, welche eine mehr oder weniger lückenlose Rekonstruktion der Gletscherbewegung erlauben und einer klimatischen Interpretation genügen. Wir kennen von der Mehrzahl der bisher untersuchten Alpengletscher ausschließlich Hochstandsphasen, so daß für viele Gletscher lediglich eine Auflistung der Hochstände möglich ist, nicht aber das Zeichnen einer Schwankungskurve.

Hochstandswälle dokumentieren zweifellos Gletschervorstöße und ihr Alter das Ende eines gletschergünstigen Klimaabschnittes. Die Wälle sagen uns aber wenig aus über Dauer und Intensität der dem Vorstoß vorangegangenen Klimaverschlechterung. Am Beispiel der Neuzeit kann dieser Sachverhalt veranschaulicht werden:

Sowohl um 1600/1650, um 1820 als auch um 1850 wuchsen die Alpengletscher zu einem Hochstand an. Moränenwälle dieser Vorstöße liegen entweder dicht nebeneinander, teilweise oder ganz übereinander. Die Gletscherstände wiesen also die gleichen Dimensionen auf. Dank des umfangreichen witterungsgeschichtlichen Datenmaterials, das PFISTER (1984) für den Zeitraum von 1525 bis 1860 aufgearbeitet und ausgewertet hat, ist man in der Lage, Klimakonstellationen, die zu Gletschervorstößen führten, quantitativ und qualitativ zu beurteilen. Es zeigt sich deutlich, daß drei wichtige Faktoren das Ausmaß eines Vorstoßes entscheidend mitbestimmen: Dauer und Intensität einer Klimaverschlechterung sowie Ausgangsposition der Gletscherzunge.

Der Hochstand um 1600 wurde durch ein Zusammenfallen schneereicher Winter mit kühlen, naßen Sommern zwischen 1570 und 1579, gefolgt von kühlnaßen Sommern zwischen 1585 und 1597 ausgelöst. Die Gletscher stirnten zu Beginn dieser Klimade- pression etwas weiter vorne als heute. Tiefe Temperaturen und im Gebirge schneereiche Sommer in den Jahren 1812 bis 1817 , also auf wenige Jahre konzentrierte schlechte Klimabedingungen, sind Ursache für den Hochstand um 1820. Die Gletscherzungen waren durch den Vorstoß um 1600 schon weit vorgeschoben; die Ausdehnung des Unteren Grindelwaldgletschers entsprach etwa derjenigen von 1870 , der Große Aletschgletscher wies eine Ausdehnung wie zwischen 1880 und 1890 auf. Der Hochstand um 1850, als Folge unterdurchschnittlicher Temperaturen von 1847 bis 1851 und schneereicher Jahre zwischen 1851 und 1853, profitierte von der schon großen Ausdehnung der Gletscher (PFISTER 1984, ZUMBÜHL 1980).

Inzwischen ist auch Datenmaterial verfügbar, das eine Erklärung des Gletscherhochstandes im 14. Jahrhundert wenigstens teilweise erlaubt (PFISTER 1985). Auch hier - wie um 1820 - genügten offenbar wenige kühle und naße Jahre, von 1342 bis 1347, um den bereits ausgedehnten Großen Aletschgletscher zu einem Hochstand anwachsen zu lassen. Die gesamte Vorstoßphase, die schließlich in einem Hochstand um 1380 (?) kulminierte, erstreckte sich vermutlich über mehrere Jahrzehnte. Der klimatische Hauptimpuls muß im 13. Jahrhundert gesucht werden, denn ein Vorstoßen des Großen Aletschgletschers bis zu einer Ausdehnung von 1920 ist dendrochronologisch bereits um 1300 nachgewiesen (HOLZHAUSER 1984).

Mit der Datierung von Gletscherhochständen allein ist bezüglich Klimageschichte also noch wenig ausgesagt. Es bedarf dazu der Kenntnis sowohl der minimalen als auch der maximalen Gletscherausdehnung zu Beginn bzw. am Ende einer Vorstoßphase. Häufig bestehen größere zeitliche Lücken von mehreren hundert Jahren zwischen zwei Gletscherhochständen. In Ermangelung genauerer Information werden solche durch ${ }^{1+} \mathrm{C}$-Daten belegte Hochstände in einer Kurve punktiert verbunden. Dabei ist die Größe der Amplitude Ermessenssache. Die Dendroklimatologie bietet hier die Möglichkeit, solche Abschnitte klimatologisch trotzdem zu deuten.

\subsubsection{Dendroklimatologische Analysen als Interpretationshilfe}

Die maximalen Spätholzdichten von Jahrringen gelten als Indikatoren für Sommertemperaturen (Juli bis September) und sind Gegenstand dendroklimatologischer Analysen (SCHWEINGRUBER et al. 1979, BIRCHER 1982, RENNER 1982). Zur Rekonstruktion der Sommertemperaturen eignen sich allein auch die Jahrringbreiten von Bäumen aus dem oberen Waldgrenzbereich (KIENAST 1985).

Die Klimaverschlechterungen, die zu den Gletschervorstößen und -hochständen der letzten 700 Jahre geführt haben, zeichnen sich in den Kurven 


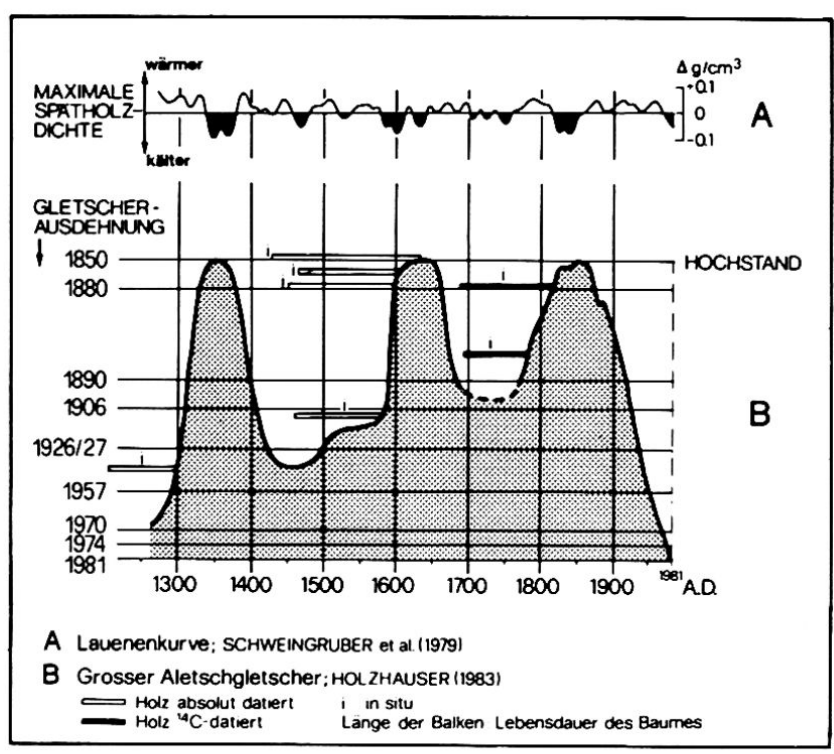

Fig. 14 Schwankungen des Großen Aletschgletschers im Vergleich mit den maximalen Spätholzdichten einer Jahrringchronologie (aus: FURRER \& HOLZHAUSER 1984)

Fig. 14 Comparison between glacier fluctuations (Großer Aletschgletscher) and maximum latewood density from a treering chronology (from FURRER \& HOLZHAUSER 1984)

der maximalen Spätholzdichten ab; jeder längeren unterdurchschnittlichen Phase im Kurvenverlauf entspricht eine Gletscherhochstandsphase, so um 1350,1600 bis 1650 und 1820 bis 1850 (Fig. 14).

Klimadepressionen können anhand von Spätholzdichtekurven auch in früheren Zeitabschnitten des Postglazials nachgewiesen werden. Mit Unterbrüchen reichen die von RENNER (1982) erarbeiteten Jahrringchronologien bis 8000 Jahre vor heute zurück. Die Phasen mit tiefen Dichtewerten stimmen mit Kaltphasen gut überein, die pollenanalytisch und gletschergeschichtlich schon festgestellt worden sind. Als extremste Kaltphase erwies sich der Zeitraum von 3340 bis 3175 vor heute ( LLöbbenkaltphase»). Neu hinzugekommen sind Chronologien von Grächen (Wallis, $1715 \mathrm{~m}$ ü. M.), die, ebenfalls mit Lücken behaftet, den Zeitraum von 6500 bis 1000 Jahre vor heute abdecken (SCHÄR \& SCHWEINGRUBER 1987). Die zum Teil ernsthaften Diskrepanzen zu den Chronologien von RENNER werden von den Autoren auf die unterschiedliche Höhenlage der Proben und auf die noch geringe Belegungsdichte der Kurven zurückgeführt. Eine Jahrringkurve der letzten rund 820 Jahre (1142-1959) liegt ebenfalls aus der Region Grächen (2200 m ü. M., HOLZHAUSER 1985) vor.

Die Gletscherhochstandsphasen der letzten Jahrhunderte sind mit fossilen Bäumen aus Hochstandsmoränen belegt. Häufig zeichnet sich die dem Glet- schervorsto $ß$ vorangegangene Klimaverschlechterung in der Ausbildung der Jahrringbreiten und -dichten ab (FURRER \& HOLZHAUSER 1984).

Holzfunde aus dem Innern des Gletschervorfeldes sind ebenfalls vorhanden. Sie belegen, wie bereits erwähnt, minimale Gletscherausdehnungen und Vorstöße über ein Niveau hinaus, das teilweise bedeutend geringer war als das Hochstandsniveau. So stie $B$ der Zmuttgletscher um 7600 yBP mindestens bis zu einer Ausdehnung wie um 1920 vor und überfuhr 300-400 Jahre alte Lärchen (RÖTHLISBERGER F. 1976: 83). Die Bäume sind nicht in situ, doch darf aufgrund des mitaufgeschlossenen Waldbodens angenommen werden, daß diese sich in etwa an Ort und Stelle noch befinden (RÖTHLISBERGER F. 1986: 68). Ähnlich alte Funde stammen aus dem Vorfeld des Glacier de Ferpècle (RÖThlisberger F. et al. 1980). Diese Bäume wurden zusammen mit einem Baum aus Saas Fee dendroklimatologisch ausgewertet (BIRCHER 1982: 105). Ebenfalls belegt ist ein Vorstoß des Großen Aletschgletschers um 1550 yBP über eine Ausdehnung von 1920 hinaus (HOLZHAUSER 1984); bis zu 390 Jahre alte Lärchen deckte der Gletscher damals zu. Auch von diesen Bäumen existiert eine Mittelkurve der maximalen Spätholzdichten.

Fig. 15 zeigt die Dichtekurven der Bäume aus den Vorfeldern des Glacier de Ferpècle und des GroBen Aletschgletschers. Bis zu drei unterdurchschnittliche Klimaphasen zwischen 65 und 90 Jahren Dauer sind erkennbar (in der Figur schwarz eingezeichnet). Diese Abschnitte wiesen durchaus Temperaturverhältnisse auf, wie wir sie von den Kaltphasen der Neuzeit her kennen: Nach RENNER (1982: 57) ist beispielsweise der Abschnitt $7830-7740$ vor heute an Intensität vergleichbar mit der Klimaverschlechterung in der ersten Hälfte des 19. Jahrhunderts.

Obwohl dendroklimatologisch mehrere kühlere Phasen, sehr wahrscheinlich begleitet von Gletschervorstößen, nachgewiesen sind, ist die "Gletscherkurve» nur gestrichelt darstellbar (Fig. 16). Der Kurvenverlauf täuscht gletschergeschichtlich "ruhige» Abschnitte vor, obwohl vielleicht die Gletscher mit neuzeitlichen Amplituden schwankten, jedoch innerhalb einer anderen Bandbreite. Die Annahme einer sehr geringen Gletscherausdehnung über jeweils rund 400 Jahre scheint sich damit aufzudrängen.

In dieser Beziehung sind die neuesten Untersuchungen von PORTER \& OROMBELLI (1985) von besonderer Bedeutung: Ihren Ausführungen zufolge ist der Ruitorgletscher von $8395 \pm 125$ bis $6270 \pm 75$ vor heute nie über die Ausdehnung von 1977 hinaus vorgestoßen. Wie dieser Befund mit dem Vorstoß des Zmuttgletschers und des Glacier de Ferpècle (Ausdehnung von 1920) in Einklang zu bringen ist, muß durch weitere Untersuchungen abgeklärt werden. 


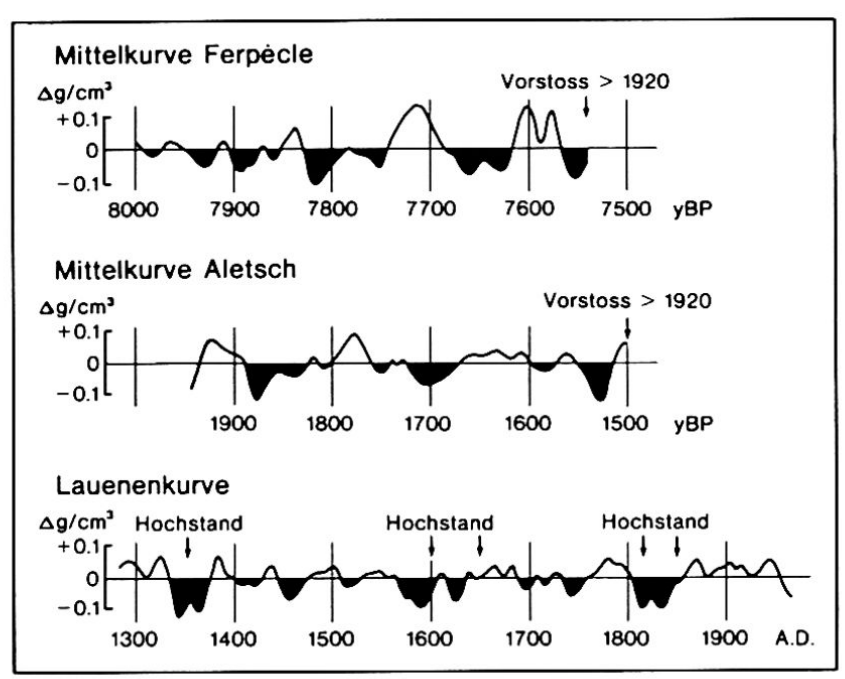

Fig. 15 Maximale Spätholzdichtekurven aus verschiedenen postglazialen Zeitabschnitten. Quellen: RENNER (1982), RÖTHLISBERGER F. (1976, 1986), HOLZHAUSER (1984) und SCHWEINGRUBER et al. (1979)

Fig. 15 Maximum latewood density in different holocene periods (from RENNER 1982, RÖTHLISBERGER F. 1976/1986, HOLZHAUSER 1984 and SCHWEINGRUBER et al. 1979)

Grosser Aletschgletscher: Vorstoss um 1500 yBP
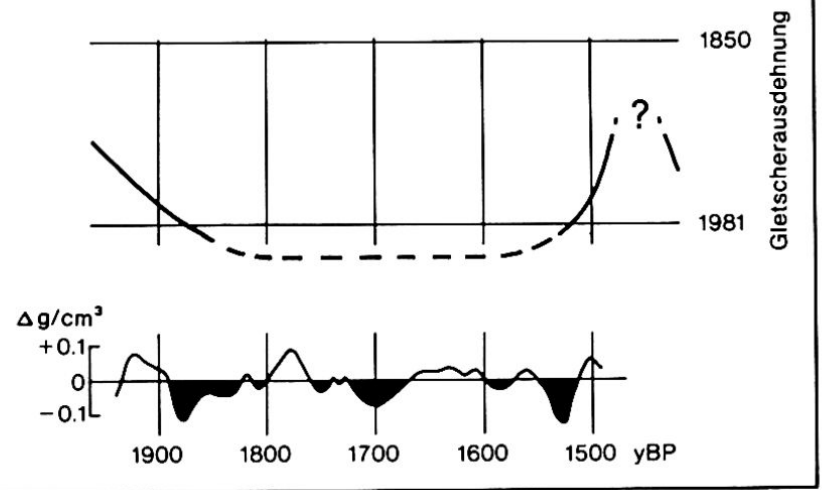

Fig. 16 Vergleich "Gletscherkurve" mit Kurve der maximalen Spätholzdichten. Quelle: HOLZHAUSER (1984)

Fig. 16 Comparison between "glacier curve" and maximum wood density (from HOLZHAUSER 1984)

Vielleicht schimmern hier regionalklimatische Unterschiede oder ein gletscherindividuell verschiedenes Verhalten durch.

\subsubsection{Verschiedene "Schwankungsniveaus"}

Der Gedanke, verschiedene «Schwankungsniveaus» der Gletscher in Betracht zu ziehen, liegt nahe. Wir orientieren uns beim Zeichnen von post- glazialen "Gletscherkurven" an neuzeitlichen Verhältnissen und sind allzusehr an dieser Bandbreite möglicher Gletscherschwankungen - zwischen Hochstand 1850 und «heutiger» Ausdehnung - fixiert. Dabei geht es nicht darum, die Definition «Hochstand» im Sinne von maximaler postglazialer Ausdehnung in Frage zu stellen, denn diese Größenordnung ist durch Moränenwälle belegt. Vielmehr geht es darum, die Untergrenze der gemeinhin für das Postglazial als repräsentativ angenommenen Bandbreite zu relativieren.

Bis heute kann der Nachweis, wie weit die Alpengletscher im Postglazial maximal zurückgeschmolzen waren, nicht erbracht werden. Einige fossile Böden und Hölzer innerhalb des Vorfeldes weisen höchstens darauf hin, daß die Gletscher auch schon kleiner als heute waren. Die dendroklimatologische Auswertung fossiler Hölzer läßt zudem erahnen, daß sie zeitweise sogar sehr weit hinter dem heutigen Zungenende stirnten. Die neuzeitliche Bandbreite ist für solche Ausdehnungen zu eng gefaßt. Es bedarf eines anderen «Schwankungsniveaus».

Ein Modell, wie man sich die verschiedenen $\mathrm{Ni}$ veaus vorstellen kann, vermittelt Fig. 17. Innerhalb jeder Bandbreite können die Gletscher starken Schwankungen unterworfen sein. Es ist vorstellbar, daß beispielsweise ein "Hochstand" in einem unteren Niveau der Ausdehnung von etwa 1920 oder gar der «heutigen» Ausdehnung entsprochen haben könnte.

Für das Wechseln von einem zum anderen «Schwankungsniveau» bedarf es natürlich einschneidender Klimaänderungen, die bewirken, daß die Gletscher entweder weit über die bestehende Bandbreite vorstoßen oder weit unter diese zurückschmelzen. Nach einer gewissen Zeit können sich durchaus wieder «normale» Klimabedingungen - selbstverständlich mit der ganzen neuzeitlichen Variabilität - einstellen.

Abrupte Klimaänderungen - sogenannte Klimastürze - sind mit Hilfe der Dendroklimatologie nachgewiesen. Eine drastische Änderung ist zum Beispiel um 3340 yBP zu verzeichnen (RENNER 1982): Die Sommertemperaturen sanken innerhalb weniger Jahre weit unter den Mittelwert, wo sie dann über längere Zeit (165 Jahre) verharrten. Dieser Klimasturz, verbunden mit Gletscherhochständen, ist nach bisherigen Erkenntnissen der intensivste innerhalb des Postglazials. Weitere Klimastürze ereigneten sich nach RENNER um 6550 yBP (Dauer: 150 Jahre) und um 5275 yBP (Dauer: 125 Jahre). Auch hier sind Gletschervorstöße mit anschließenden Hochständen nachgewiesen (vgl. AMMANN 1978, RENNER 1982 und MEIER unpubl.). Umgekehrt sind auch Zeitabschnitte mit überdurchschnittlichen Klimaverhältnissen bekannt, so zum Beispiel zwischen 4400 bis 3600 yBP: Die Waldgrenze lag damals - wenigstens zeitweise - gegenüber heute bis 


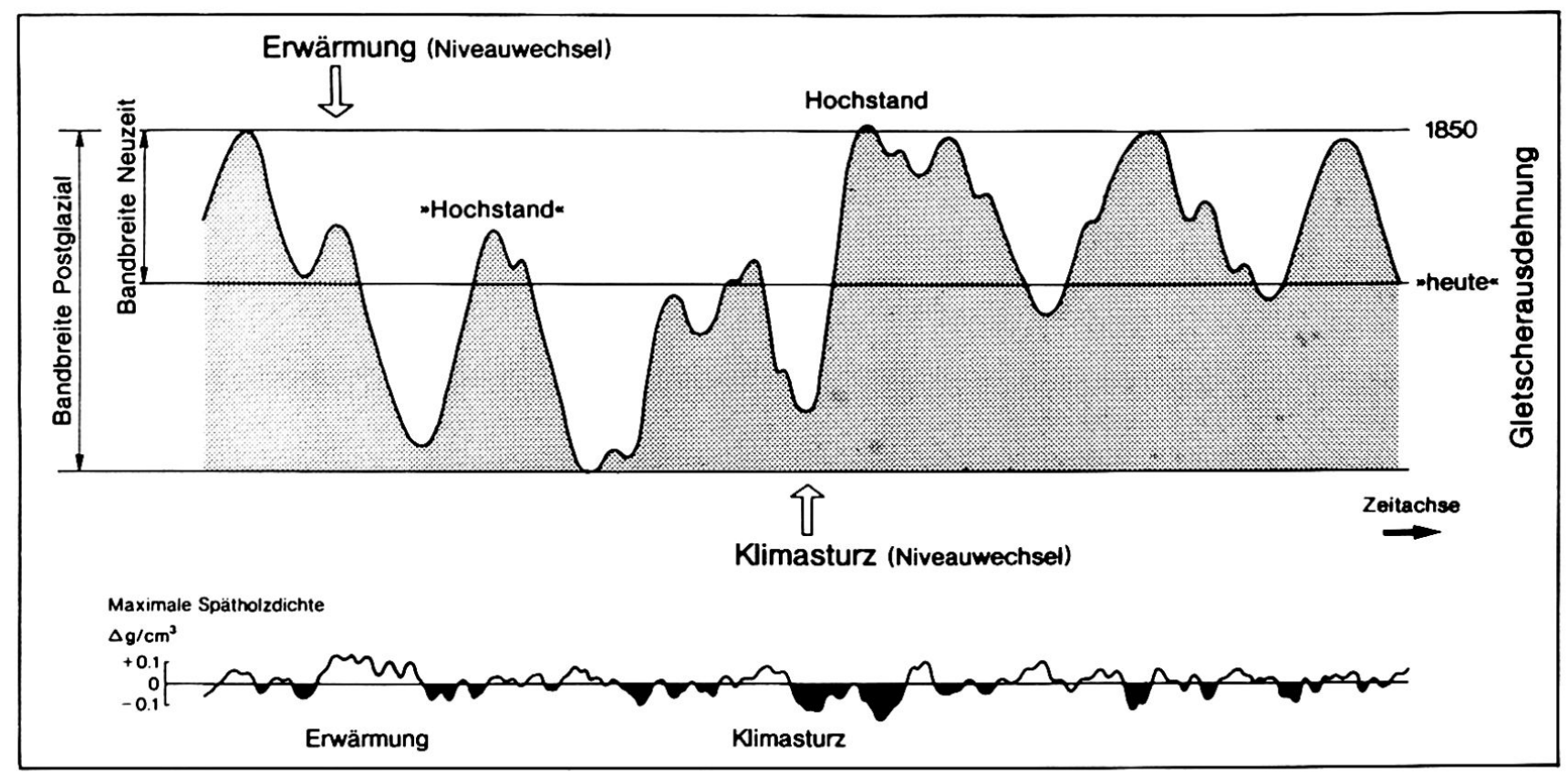

Fig. 17 Modell, das von zwei verschiedenen "Schwankungsniveaus" ausgeht, einem "oberen" (neuzeitlichen) und einem "unteren"

Fig. 17 A schematic diagram of two possible glacier fluctuation levels during the Holocene.

zu hundert Meter höher (s. GAMPER \& SUTER 1982, FURRER \& HOLZHAUSER 1984). Gletscherhochstände sind in diesem Zeitraum bisher noch keine bekannt. Offenbar pendelten die Gletscher innerhalb eines unteren "Schwankungsniveaus». Ein modellhafter Verlauf der maximalen Spätholzdichten ist in Fig. 17 entsprechend den Gletscherschwankungen dargestellt.

Der Mangel an gesicherten gletschergeschichtlichen ${ }^{1+} \mathrm{C}$-Daten in der ersten Hälfte des Postglazials gibt Anlaß zur Vermutung, daß die Gletscher innerhalb einer anderen Bandbreite schwankten (Fig. 18, 19). Es ist anzunehmen, daß einige fossile Böden und Hölzer, die Vorstöße auch in diesem Zeitraum belegen könnten, noch unter dem Eis oder in den Ufermoränen verborgen liegen. In den aufgeschlossenen Kernen von hohen Ufermoränen wies diesbezüglich RÖTHLISBERGER F. (1986) im Himalaya frühe postglaziale Vorstöße nach. GAMPER (1986) macht für das Fehlen von Daten klimatische Gründe geltend: Das vermehrte Auftreten längerer Solifluktionsphasen und (nachweisbarer) Gletschervorstöße in der zweiten Hälfte des Postglazials ist als Resultat einer Klimaänderung zu werten. Einem Abschnitt mit eher ozeanisch geprägten Klimaverhältnissen folgte eine Phase mit verstärkter Kontinentalität (schneearme und kalte Winter, kühle Sommer), einhergehend mit einer geringen $\mathrm{Ab}$ nahme der Jahresmitteltemperatur. Diesem Wech- sel entspricht wahrscheinlich der von RENNER (1982) nachgewiesenen Klimasturz um 5275 yBP und damit auch die ersten gesicherten, im Endmoränenbereich nachgewiesenen Gletscherhochstände mit neuzeitlichen Dimensionen.

Die Ergebnisse von PORTER \& OROMBELLI (1985) sind mit diesem Sachverhalt also durchaus vereinbar; die Annahme eines unteren «Schwankungsniveaus» der Gletscher in der ersten Hälfte des Postglazials scheint damit gerechtfertigt. Die Gletscher stirnten während ihren "Höchständen» im Innern des $1850 \mathrm{er}$-Vorfeldes; die allfällig abgelagerten Endmoränen sind von nachfolgenden GletschervorstöBen verwischt worden.

Nach rund 6000 yBP sind aufgrund der bisherigen Resultate drei Phasen nachgewiesen, die eine andere Bandbreite der Gletscherschwankungen vermuten lassen: Zwischen 5700(?) und 5300 yBP sowie zwischen den bereits erwähnten Abschnitten von 4400-3600 yBP und von 1900-1500 yBP. Der letzte Niveauwechsel erfolgte um 1500 yBP. Innerhalb der letzten 1500 Jahre wechselten sich größere Vorstoß- mit Rückschmelzphasen in Abständen von rund 200-250 Jahren ab, wie das die gutbelegte Kurve des Großen Aletschgletschers zeigt (HOLZHAUSER 1984). Das "Schwankungsniveau» dürfte also etwa gleichgeblieben sein, was natürlich geringfügig kleinere Ausdehnung als heute über kürzere Zeit nicht ausschließt (z. B. zwischen 650 und 750 


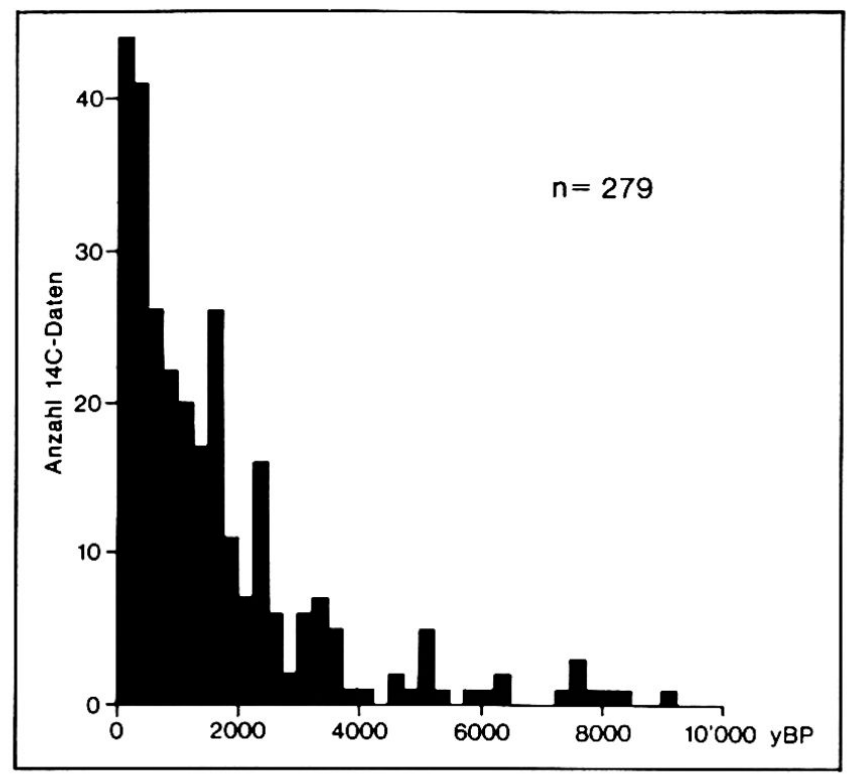

Fig. 18 Histogramm aller gletschergeschichtlich aussagekräftigen ${ }^{14} \mathrm{C}$-Daten innerhalb des Postglazials (Klassenbreite: 250 Jahre; Stand 1986)

Fig. 18 Distribution of all the ${ }^{14} \mathrm{C}$-dates relating to the holocene glacier fluctuations (range of the classes: 250 years)

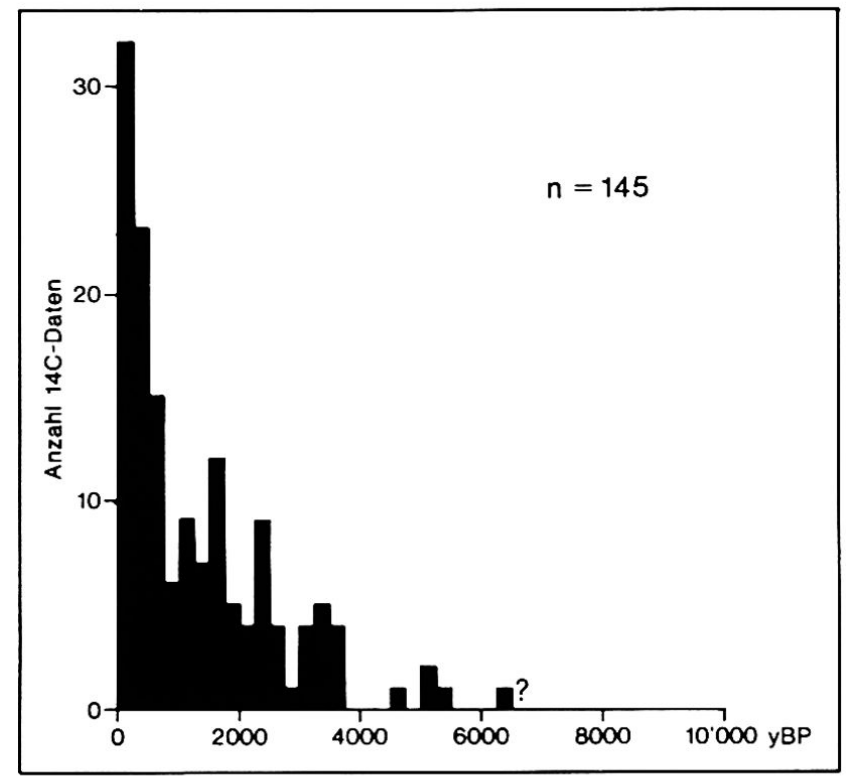

Fig. 19 Histogramm aller ${ }^{14} \mathrm{C}$-Daten, die einen Gletscherhochstand ("1850er-Ausdehnung") innerhalb des Postglazials belegen (Klassenbreite: 250 Jahre; Stand 1986)

Fig. 19 Distribution of all the ${ }^{14} \mathrm{C}$-dates relating to a maximum extension ("1850-extension") during the Holocene (range of the classes: 250 years)

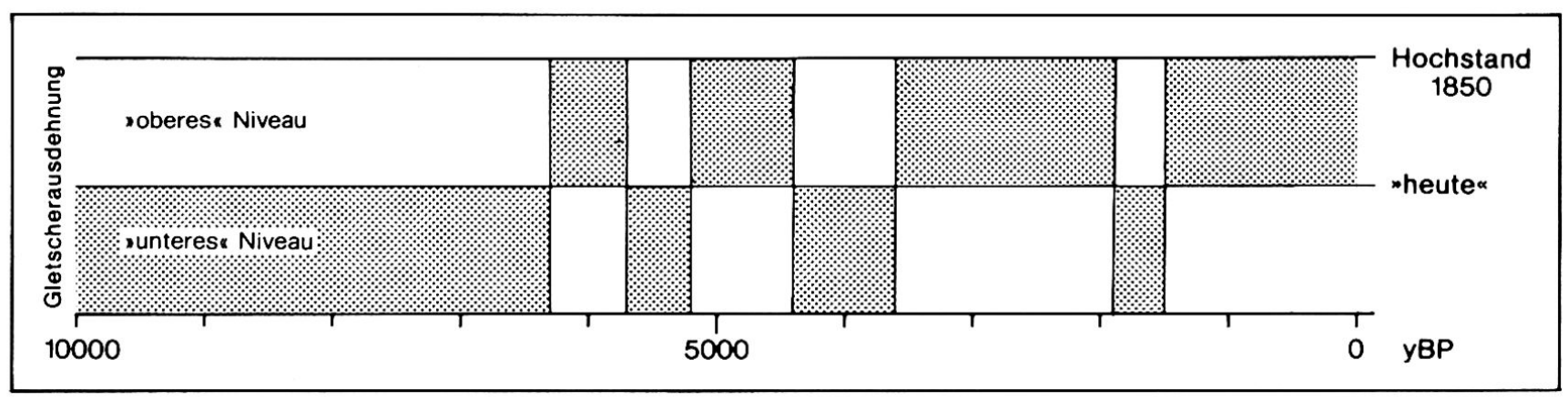

Fig. 20 Mögliche Schwankungsniveaus im Postglazial (schematisch)

Fig. 20 Possible fluctuation levels during the Holocene

A. D. und zwischen 970 und 1050 A. D.). Fig. 20 hält schematisch die möglichen Schwankungsbereiche im Postglazial fest. Dabei wurden nur zwei Niveaus berücksichtigt, ein oberes (neuzeitliches) und ein unteres. Zwischenformen sind natürlich auch denkbar. Die dunklen Balken im oberen «Schwankungsniveau» decken sich mit den Abschnitten, wo Gletscherhochstände (im Sinne neuzeitlicher Hochstände) nachgewiesen wurden. Aufgrund der vorhandenen ${ }^{{ }^{+} \mathrm{C}}$-Daten darf angenommen werden, daß die Gletscherhochstände der letzten rund 5200 Jahre vollständig erfaßt sind.

\subsection{Schlu $\beta$}

Im vorliegenden Beitrag wurde versucht darzulegen, auf was für Datengrundlagen eine «Gletscherkurve» aufgebaut ist. Der Umstand, daß wir hauptsächlich Gletscherhochstände erfassen und über die minimale Gletscherausdehnung zwischen zwei Vorstößen wenig wissen, verunmöglicht eine lückenlose Rekonstruktion der Gletscherschwankungen. Die Kenntnis des Vorstoß- bzw. Rückschmelzbetrages ist aber Voraussetzung, um das Ausmaß der auslösenden Klimaänderung beurteilen zu können. 
Etwa die erste Hälfte und einige längere Abschnitte in der zweiten Hälfte des Postglazials sind bezüglich Gletscherschwankungen nicht oder nur ungenügend dokumentiert. Innerhalb solcher Phasen sind bisher keine Gletscherhochstände in der Größenordnung des $1850 \mathrm{er}-\mathrm{Standes}$ nachgewiesen worden. Eine Möglichkeit, diese gletschergeschichtlich "stummen" Abschnitte klimageschichtlich trotzdem zu deuten, ist mit der dendroklimatologischen Analyse von fossilen Hölzern gegeben. Modellhaft wird gezeigt, wie sich gletschergeschichtliche und dendroklimatologische Ergebnisse gut ergänzen können. Die allgemein verbreitete Formulierung, daß die Gletscher im Verlauf der letzten rund 10000 Jahre um neuzeitliche Verhältnisse schwankten, trifft vermutlich nur für einzelne Abschnitte des Postglazials zu. Es gab offensichtlich Phasen, während denen die Alpengletscher sehr viel kleiner als heute waren und sich innerhalb eines anderen "Schwankungsniveaus» bewegten.

\section{Zusammenfassung}

Eine Analyse bisher publizierter Schneegrenzwerte aus Gletschergebieten zwischen Unter-Engadin und Mont Blanc zeigt, daß die Depressionswerte für die spätglazialen Stadien Gschnitz, Clavadel, Daun und Egesen keine räumlich bedingten signifikanten Unterschiede aufweisen. Eine darauf aufbauende klimageographische Interpretation (Variationen des Niederschlagsverhaltens) scheint damit außer Betracht zu fallen. Größere Abweichungen von den errechneten Mittelwerten können mit der Individualität der untersuchten Gletscher (z. B. Topographie des Gletscherlängsprofiles) erklärt werden und liegen zumeist auch innerhalb des Schwankungsbereiches des als «konstant» angenommenen 2:1-Teilungsverhältnisses. Die bisher erarbeiteten Kennwerte für die Stadien Gschnitz, Clavadel, Daun und Egesen wurden tabelliert und widerspiegeln die typischenWertebereiche und die bei der Betrachtung von Einzelgletschern zu erwartende Variation.

Die Vegetationsgeschichte liefert Hinweise zur Paläoklimatologie und Florengeschichte sowie zu Waldgrenzschwankungen und erlaubt die biostratigraphische Gliederung von Profilmaterial. Die Vegetationsverhältnisse während der Ältesten Dryas sind für die ganze Schweiz durch eine große Einförmigkeit gekennzeichnet. Es sind dies vorwiegend Rohböden- bzw. Steppengesellschaften, die von $A r$ temisia, Chenopodiaceae, Ephedra, Gypsophila, Saxifraga spec., Helianthemum, Thalictrum, Juniperus und Betula nana gebildet werden. Die bisher ältesten Spätglazial-Alter in Schweizer Mooren liegen zwischen 13000 und 14000 Jahre BP. Die Figur 11 zeigt die Entwicklung des zentralalpinen Waldgürtels der Schweiz seit der Späteiszeit.

Postglaziale Schwankungen der geomorphologischen Aktivität in den Alpen können mit Hilfe der ${ }^{1+} \mathrm{C}$-Datierung fossiler Böden in Erdströmen, Moränen und Schutthalden rekonstruiert werden. Eine Analyse der Häufigkeitsverteilung von 14C-Daten aus dem Alpenraum zeigt, daß die geomorphologische Aktivität bis 4500 vor heute eher gering war, die zweite Hälfte des Postglazials ist dagegen durch häufige Wechsel von Phasen geomorphologischer Aktivität und Stabilität gekennzeichnet.

Unterschiedliche Aussagekraft, begrenztes zeitliches Auflösungsvermögen der gletschergeschichtlichen Daten sowie das Fehlen von nachweisbaren Gletschervorstößen innerhalb größerer Abschnitte des Postglazials verunmöglichen eine lückenlose Rekonstruktion der Gletscherbewegungen. Anhand eines Modells, das sowohl gletschergeschichtliche als auch dendroklimatologische Befunde miteinbezieht, wird gezeigt, daß die Alpengletscher vermutlich innerhalb verschiedener "Niveaus" geschwankt haben, wovon eines das «neuzeitliche» ist.

\section{Literatur (Auswahl)}

AESCHLIMANN, H. (1983): Zur Geschichte des italienischen Mont-Blanc-Gebietes: Val Veni - Val Ferret - Ruitor. Diss. Univ. Zürich.

BADER, S. (1986): Beitrag zur Geomorphologie sowie zur spätglazialen Gletschergeschichte des Schilstales (St. Galler Oberland). Unveröff. Diplomarbeit Geogr. Inst. Univ. Zürich: $89 \mathrm{~S}$.

BEELER, F. (1977): Geomorphologische Untersuchungen am Spät- und Postglazial im Schweizerischen Nationalpark und im Berninapaßgebiet (Südrätische Alpen). Ergebnisse der wissenschaftlichen Untersuchungen im Schweizerischen Nationalpark XV, 77: 131-276.

BEUG, H. J. (1982): Vegetation history and climatic changes in central and southern Europe. In: Harding A. F. (Edit.): Climatic Changes in Later Prehistory, 85-102.

BIRCHER, W. (1982): Klima- und Gletschergeschichte des Saastales: Glazialmorphologische und dendroklimatologische Untersuchungen. Phys. Geographie, Vol. 9. Zürich.

BIRKS; H. J. B. (1981): The use of pollen analysis in the reconstruction of past climates: a review. In: Climate and History, ed. by T.M. L. Wigley et al., 111-138.

BLESS, R. (1984): Beiträge zur spät- und postglazialen Geschichte der Gletscher im nordöstlichen Mont Blanc-Gebiet. Phys. Geographie, Vol. 15. Zürich. 
BOREL, J. L., JORDA, M. und MONJUVENT, G. (1984): Variations climatiques, morphogenèse et évolution de la végétation post-würmiennes dans les Alpes françaises. In: "Les Alpes", $25^{\circ}$ Congr. Internat. de Géographie, Paris: 43-53.

BURGA, C. (1980): Pollenanalytische Untersuchungen zur Vegetationsgeschichte des Schams und des San Bernardino-Paßgebietes (Graubünden, Schweiz). Diss. Bot. 56: $194 \mathrm{~S}$.

BURGA, C. (1982 a): Überblick zur palynologischen Erforschung Graubündens 1929-1982. Phys. Geographie, 1: 147-156.

BURGA, C. (1982 b): Pollenanalytical research in the Grisons (Switzerland). An overview from 1929 to 1981 and some results concerning the history of vegetation since the Late Glacial. Vegetatio, 49: 173-186.

BURGA, C. (1984): Beobachtungen zum Lineargefüge des Adula-Kristallins und zum Quartär am San-Bernardino-Paß (Graubünden/Schweiz). In: Geographica Helvetica, 1/84: 27-33.

BURGA, C. (1987): Gletscher- und Vegetationsgeschichte der südrätischen Alpen seit der Späteiszeit (Puschlav, Livigno, Bormiese). Denkschriften der Schweiz. Naturf. Ges. Bd. 101.

EICHER, U. (1979): Die ${ }^{18} \mathrm{O} /{ }^{16} \mathrm{O}-$ und ${ }^{13} \mathrm{C} /{ }^{12} \mathrm{C}$-Isotopenverhältnisse in spätglazialen Süßwasserkarbonaten und ihr Zusammenhang mit den Ergebnissen der Pollenanalyse. Diss. Univ. Bern: 205 S.

FIRBAS, F. (1949/52): Spät- und nacheiszeitliche Waldgeschichte Mitteleuropas nördlich der Alpen. 2 Bde.

FITZE, P. (1982): Einige Bemerkungen zum Zeitfaktor bei der Bodenbildung. Phys. Geographie, 1: 73-82.

FLOHN, H. (1985): Das Problem der Klimaänderungen in Vergangenheit und Zukunft. Wiss. Buchges. Darmstadt, Bd. 220: 228 S.

FRANZONI, M. (1985): Gletschergeschichtliche Untersuchungen im "Klöntaler Raum»/Kanton Glarus. Unveröff. Diplomarbeit Geogr. Inst. Univ. Zürich: $78 \mathrm{~S}$.

FRENZEL, B. (1980): Klima der Letzten Eiszeit und der Nacheiszeit in Europa. Veröff. Joachim Jungius-Ges. Wiss. Hamburg, 44: 9-46.

FURRER, G. (1954): Solifluktionsformen im Schweizerischen Nationalpark. Erg. wiss. Erforsch. Nationalparks, 4/29: 202-275.

FURRER, G. (1977): Klimaschwankungen im Postglazial im Spiegel fossiler Böden. Ein Versuch im Schweizerischen Nationalpark. Erg. wiss. Erforsch. Nationalparks, 13:267-270.

FURRER, G., BACHMANN, F. und FITZE, P. (1971): Erdströme als Formelemente von Solifluktionsdecken im Raum Munt Chavagl/Munt Buffalora (Schweiz. Nationalpark). Ergebnisse der wissenschaftlichen Untersuchungen im Schweizerischen Nationalpark XI, 65: 189-269.

FURRER, G., GAMPER-SCHOLLENBERGER, B. und SUTER, J. (1978): Zur Geschichte unserer Gletscher in der Nacheiszeit. Methoden und Ergebnisse. In: Jb. Schweiz. natf. Ges., wissenschaftl. Teil, 1978: 76-88. Basel/Boston/ Stuttgart.

FURRER, G. und HOLZHAUSER, H. (1984): Gletscher- und klimageschichtliche Auswertung fossiler Hölzer. In: Z. Geomorph. N. F., Suppl.-Bd. 50: 117-136. Berlin/Stuttgart.
FURRER, G., MAISCH, M. und BURGA, C. (1984): Übersicht zur spät- und postglazialen Klima-, Gletscher- und Vegetationsgeschichte Graubündens. Diss. Bot. (Festschr. Welten), 72: $87-115$.

GAILLARD, M.-J. (1984): Etude Palynologique de l'Evolution Tardi- et Postglaciaire de la Végétation du Moyen-Pays Romand (Suisse). Diss. Bot. 77: 322 S.

GAILLARD, M.-J., REYNAUD, C., WEBER, B. und WEGMÜLLER, S. (1981): Les variations tardiglaciaires et postglaciaires du niveau du lac Léman: apport des données palynologiques. Aperçu bibliographique. Arch. suisses d'anthropologie générale, 45/2: 117-121.

GAMPER, M. (1981): Heutige Solifluktionsbeträge von Erdströmen und klimamorphologische Interpretation fossiler Böden. Ergebnisse der wissenschaftlichen Untersuchungen im Schweizerischen Nationalpark XV, 79: 355-443.

GAMPER, M. (1982): Beiträge zur Quartärforschung in der Schweiz. (Herausgeber) Phys. Geographie 1: 257 S.

GAMPER, M. (1983): Controls and rates of movement of solifluction lobes in the Eastern Swiss Alps. In: Permafrost: Fourth International Conference, Proceedings: 328-333.

GAMPER, M. (1985): Morphochronologische Untersuchungen an Solifluktionszungen, Moränen und Schwemmkegeln in den Schweizer Alpen. Eine Gliederung mit Hilfe der ${ }^{14} \mathrm{C}$-Altersbestimmung fossiler Böden. Phys. Geographie, Vol. 17. Zürich.

GAMPER, M. und SUTER, J. (1978): Der Einfluß von Temperaturänderungen auf die Länge von Gletscherzungen. Geographica Helvetica, 33. Jg., H. 4: 183-189. Bern.

GAMPER, M. und OBERHÄNSLI, H. (1982): Interpretation von Radiokarbondaten fossiler Böden. Phys. Geographie 1: 83-90.

GAMPER, M. und SUTER, J. (1982): Postglaziale Klimageschichte der Schweizer Alpen. In: Geographica Helvetica, 37 Jg., H. 2: 105-114. Zürich.

GEYH, M. (1983): Physikalische und chemische Datierungsmethoden in der Quartärforschung. Clausthaler Tektonische Hefte 19

GRONER, U. (1986): Zur Problematik von umgelagerten Palynomorphen in Glazial- und Spätglazialsedimenten des Schweizer Mittellandes. Eclogae geol. Helv., 79,3: 617-639.

GROSS, G., KERSCHNER, H. und PATZELT, G. (1978): Methodische Untersuchungen über die Schneegrenze in alpinen Gletschergebieten. Zeitschr. für Gletscherkunde und Glazialgeologie, Band 12, Heft 2, 1976.

HAEBERLI, W. (1982): Klimarekonstruktionen mit GletscherPermafrost-Beziehungen. Mat. zur Physiogeographie, Vol. 4: 9-17.

HAEBERLI, W. (1983): Permafrost-glacier relationships in the Swiss Alps - today and in the past. In: Proceedings Forth International Conference on Permafrost, p. 415-420.

HANTKE, R. (1978-1983): Eiszeitalter. 3 Bde.: 1901 S.

HARTMANN-BRENNER, D. (1973): Ein Beitrag zum Problem der Schutthaldenentwicklung an Beispielen des Schweizerischen Nationalparks und Spitzbergens. Diss. Univ. Zürich.

HEITZ, A.-K. (1982): Vegetations-, Klima- und Gletschergeschichte des Oberengadins. Phys. Geographie 1: 157-170.

HEITZ, C. (1975): Vegetationsentwicklung und Waldgrenzschwankungen des Spät- und Postglazials im Oberhalbstein (Graubünden/Schweiz) mit besonderer Berücksichtigung der Fichteneinwanderung. Beitr. z. geobot. Landesaufn. d. Schweiz, 55: 63 S. 
HEUBERGER, H. (1980): Die Schneegrenze als Leithorizont in der Geomorphologie. C. JENTSCH und H. LIEDTKE (Hrsg.): Höhengrenzen in Hochgebirgen. Arbeiten aus dem Geogr. Inst. der Univ. des Saarlandes, Bd. 29: 35-48.

HOFFMANN, A. (1957): Evolution postglaciaire de la fôret et des tourbières dans les Alpes Glaronnaises. Ber. Geobotan. Inst. Rübel in Zürich: 76-122.

HOLZHAUSER, H. (1982): Neuzeitliche Gletscherschwankungen. In: Geographica Helvetica, H. 2, 115-126.

HOLZHAUSER, H. (1984 a): Rekonstruktion von Gletscherschwankungen mit Hilfe fossiler Hölzer. Geographica Helvetica, 39. Jg., H. 1: 3-15. Zürich.

HOLZHAUSER. H. (1984 b): Zur Geschichte der Aletschgletscher und des Fieschergletschers. Phys. Geographie, Vol. 13. Zürich.

HOLZHAUSER, H. (1985): Neue Ergebnisse zur Gletscherund Klimageschichte des Spätmittelalters und der Neuzeit. Geographica Helvetica, 40. Jg., H. 4: 168-185. Zürich.

HUBSCHMID, F. und LANG, G. (1985): Les Embreux - Holocene environments of a mire in the Swiss Jura mountains. Dis.. Bot. 87: 115-126.

JORAY; M. (1942): L'Etang de la Gruyère. Etude pollenanalytique et stratigraphique de la tourbière. Beitr. z. geobot. Landesaufn. d. Schweiz, 25: 117 S.

JORDI; U. (1986): Glazialmorphologische und gletschergeschichtliche Untersuchungen im Taminatal und im Rheintalabschnitt zwischen Flims und Feldkirch (Ostschweiz, Vorarlberg). Diss. Univ. Bern, $168 \mathrm{~S}$.

KELLER, P. (1928): Pollenanalytische Untersuchungen an Schweizer Mooren und inre florengeschichtliche Deutung. Veröff. Geobot. Inst. Rübel in Zürich, 5.

KELLER, P. (1930): Postglaziale Waldperioden in den Zentralalpen Graubündens. Beih. Bot. Cbl. 46/ll: 395-489.

KELLER, P. (1935): Pollenanalytische Untersuchungen an Mooren des Wallis. Vjschr. Naturf. Ges. in Zürich, 80: 17-74.

KERSCHNER, H. (1982): Outlines of the climate during the Egesen advance (Younger Dryas, $11000-10000$ BP) in the central Alps of the western Tyrol, Austria. Zeitschr. für Gletscherkunde und Glazialgeologie, Band 16, Heft 2: 229-240.

KERSCHNER, H. (1983): Late-glacial paleotemperatures and paleoprecipitation as derived from permafrost: glacier relationsships in the Tyrolean Alps, Austria. Proceedings Fourth International Conference on Permafrost: 589-594.

KIENAST, F. (1985): Dendroökologische Untersuchungen an Höhenprofilen aus verschiedenen Klimabereichen. Diss. Univ. Zürich.

KLEIBER, H. (1974): Pollenanalytische Untersuchungen zum Eisrückzug und zur Vegetationsgeschichte im Oberengadin. Bot. Jb. Syst., 94/1: 1-53.

KRAL, F. (1979): Spät- und postglaziale Waldgeschichte der Alpen auf Grund der bisherigen Pollenanalysen. Veröff. Inst. f. Waldbau Univ. f. Bodenkultur in Wien: $175 \mathrm{~S}$.

KÜTTEL, M. (1979): Pollenanalytische Untersuchungen zur Vegetationsgeschichte und zum Gletscherrückzug in den westlichen Schweizer Alpen. Ber. Schweiz. Bot. Ges., 89/ 1-2: 9-62.

LANG, G. (1985 a): Palynologic research in Switzerland 1925-1985. A documentation of investigations concerning the last 15,000 years. Diss. Bot. 87: 11-82.

LANG, G. (1985 b): Palynologic and stratigraphic investigations of Swiss lake and mire deposits. A general view over a research programme. Diss. Bot. 87: 107-114.
LANG, G. und TOBOLSKI, K. (1985): Late-glacial and holocene environments of a lake at the timberline in the Central Swiss Alps. Diss. Bot. 87: 209-228.

LISTER, G. und KELTS, K. (1984): Correlation of the paleoclimatic record in lacustrine sediment sequences: ${ }^{14} \mathrm{C}$ dating by AMS. Nuclear Instr. and Meth. in Physics. Res. B5: 389-393.

LOTTER, A. (1985): Amsoldingersee - Late-glacial and holocene environments of a lake at the southern edge of the Swiss Plateau. Diss. Bot. 87: 185-208.

LÜDI, W. (1935): Das Große Moos im westschweizerischen Seelande und die Geschichte seiner Entstehung. Veröff. Geobot. Inst. Rübel in Zürich, 11: 344 S.

MAISCH, M. (1981): Glazialmorphologische und gletschergeschichtliche Untersuchungen im Gebiet zwischen Landwasser- und Albulatal (Kt. Graubünden, Schweiz). Phys. Geographie, Vol. 3. Zürich.

MAISCH, M. (1982): Zur Gletscher- und Klimageschichte des alpinen Spätglazials. Geographica Helvetica, H. 2: 93-104, Zürich.

MARKGRAF, V. (1970 a): Waldgeschichte im Alpenraum seit der letzten Eiszeit. Umschau, 24: 789-790.

MARKGRAF, V. (1970 b): Palaeohistory of the Spruce in Switzerland. Nature, 228/5268: 249-251.

MARKGRAF, V., BRADBURY, J. P. und BUSBY, J. R. (1986): Paleoclimates in Southwestern Tasmania during the Last 13,000 Years. Palaios, $1: 368-380$.

MATTHEY, F. (1971): Contribution à l'étude de l'évolution tardi- et postglaciaire de la végétation dans le Jura central. Beitr. z. geobot. Landesaufn. d. Schweiz, 53: 86 S.

MÜLLER, H.-J. (1972): Pollenanalytische Untersuchungen zum Eisrückzug und zur Vegetationsgeschichte im Vorderrhein- und Lukmaniergebiet. Flora, 161: 333-382.

PENCK, A. und BRÜCKNER, E. (1909): Die Alpen im Eiszeitalter. 3 Bde., Leipzig: $1199 \mathrm{~S}$.

PFISTER, CH. (1984): Klimageschichte der Schweiz 1525-1860. Academica Helvetica, Bd. I. Bern/Stuttgart.

PFISTER, CH. (1985): Veränderungen der Sommerwitterung im südlichen Mitteleuropa von 1270-1400 als Auftakt zum Gletscherhochstand der Neuzeit. Geographica Helvetica, 40. Jg., H. 4: 196-204. Zürich.

PORTER, S. C. und OROMBELLI, G. (1985): Glacier contraction during the middle Holocene in the western Italian Alps: Evidence and implications. Geology, Vol. 13: 296-298.

PUNCHAKUNNEL, P. (1982): Pollendiagramme aus dem Oberengadin. Phys. Geographie, 6: 20-30.

RENNER, F. (1982): Beiträge zur Gletschergeschichte des Gotthardgebietes und dendroklimatologische Untersuchungen an fossilen Hölzern. Phys. Geographie, Vol. 8. Zürich.

REYNAUD, C. (1982): Sédimentologie et chronologie des formations du Pleistocène supérieur dans le sud du bassin genevois. Diss. Univ. Genève (unveröff.).

RÖSCH, M. (1983): Geschichte der Nußbaumer Seen (Kanton Thurgau) und ihrer Umgebung seit dem Ausgang der letzten Eiszeit aufgrund quartärbotanischer, stratigraphischer und sedimentologischer Untersuchungen. Mitt. Thurg. Naturf. Ges., 45: 110 S.

RÖTHLISBERGER, F. (1976): Gletscher- und Klimaschwankungen im Raum Zermatt, Ferpècle und Arolla. Die Alpen (S.A.C.), 52. Jg., Nr. 3/4: 59-152. Bern. 
RÖTHLISBERGER, F., HAAS, PH., HOLZHAUSER, H., KELLER, W. A., BIRCHER, W. und RENNER, F. (1980): Holocene Climatic Fluctuations - Radiocarbon Dating of Soil (fAh) and Woods from Moraines and Glaciers in the Alps. in: MÜLLER, F., BRIDEL, L. and SCHWABE, E., Geography in Switzerland. Geographica Helvetica, 35. Jg., H. 5: 21-52. Bern und Zürich.

RÖTHLISBERGER. F. (1986): 10000 Jahre Gletschergeschichte der Erde. Mit einem Beitrag von M. A. GEYH. Aarau/Frankfurt am Main/Salzburg.

SCHAER, E. und SCHWEINGRUBER, F. (1987): Nacheiszeitliche Stammfunde aus Grächen im Wallis. Schweizerische Zeitschrift für Forstwesen.

SCHNEEBELI, W. (1976): Untersuchungen von Gletscherschwankungen im Val de Bagnes. Die Alpen (S.A.C.), 52. Jg., Nr. 3/4: 5-57. Bern.

SCHNEIDER, R. (1978): Pollenanalytische Untersuchungen zur Kenntnis der spät- und postglazialen Vegetationsgeschichte am Südrand der Alpen zwischen Turin und Varese (Italien). Bot. Jb. Syst., 100/1: 26-109.

SCHNEIDER, R. (1985): Palynologic research in the Southern and Southeastern Alps between Torino and Trieste - A review of investigations concerning the last 15,000 years. Diss. Bot. 87: 83-106.

SIDLER, C. (1984): Palynological investigations of Zübo sediments. Contr. Sedimentology, 13: 103-114.

SUTER. J. (1981): Gletschergeschichte des Oberengadins. Untersuchungen von Gletscherschwankungen in der Err-Julier-Gruppe. Phys. Geographie, Vol. 2. Zürich.

TOBOLSKI, K. (1983): Vegetational development during the Late-Würm at Lobsigensee (Swiss Plateau). Studies in the Late Quaternary of Lobsigensee 1. Revue de paléobiol., 2/2: 163-180.

VOEGELE, A. E. (1984): Untersuchungen zur Geomorphologie und jungquarantären Talgeschichte des Dischma (Davos, Kt. Graubünden). Physische Geographie, Vol. 14, 161 S.

VUAGNEUX, R. (1983): Glazialmorphologische und gletschergeschichtliche Untersuchungen im Gebiet Flüelapass (Kt. Graubünden, Schweiz). Physische Geographie, Vol. 10, 249 S.

WEBER, B. (1977): Contribution à l'étude du tardiglaciaire de la région lémanique (le profil de St-Laurent à Lausanne) III. Etude des macrorestes végétaux. Ber. Schweiz. Bot. Ges. 87/3-4: 207-226.

WEBER, B. (1980): La végétation tardiglaciaire de la région lausannoise à la lumière des macrorestes végétaux. Diss. Univ. Lausanne.

WEGMÜLLER, H. P. (1976): Vegetationsgeschichtliche Untersuchungen in den Thuralpen und im Faningebiet (Kantone Appenzell, St. Gallen, Graubünden/Schweiz). Bot. Jb. Syst., 97/2: 226-307.

WEGMÜLLER, S. (1966): Über die spät- und postglaziale Vegetationsgeschichte des südwestlichen Jura. Beitr. z. geobot. Landesaufn. d. Schweiz, 48: 144 S.

WEGMÜLLER, S. (1980): Grundzüge der spät- und postglazialen Vegetationsgeschichte des Seelandes. Jb. Geogr. Ges. von Bern, 53/1977-79: 27-41.
WEGMÜLLER, S. (1984): Zur Ausbreitungsgeschichte von Buxus sempervirens L. im Spät- und Postglazial in Süd- und Mitteleuropa. Diss. Bot. (Festschr. Welten): 333-344.

WELTEN, M. (1944): Pollenanalytische, stratigraphische und geochronologische Untersuchungen aus dem Faulenseemoos bei Spiez. Veröff. Geobot. Inst. Rübel in Zürich, 21: 201 S.

WELTEN, M. (1952): Über die spät- und postglaziale Vegetationsgeschichte des Simmentals. Veröff. Geobot. Inst. Rübel in Zürich, 26: $135 \mathrm{~S}$.

WELTEN, M. (1972): Das Spätglazial im nördlichen Voralpengebiet der Schweiz. Ber. Deutsch. Bot. Ges., 85/1-4: 69-74.

WELTEN, M. (1979): Eis, Wasser und Mensch haben das Aaretal verändert. Ergebnisse von 50 Jahren Pollenanalyse in Bern. Mitt. Naturf. Ges. in Bern, N. F., 36: 17-40.

WELTEN, M. (1982 a): Pollenanalytische Untersuchungen im Jüngeren Quartär des nördlichen Alpen-Vorlandes der Schweiz. Beitr. z. Geol. Karte der Schweiz, N. F.: 156.

WELTEN, M. (1982 b): Vegetationsgeschichtliche Untersuchungen in den westlichen Schweizer Alpen: Bern-Wallis. Denkschriften der Schweiz. Naturf. Ges., Bd. 95: 104 S.

WETTER, W. (1987): Spät- und postglaziale Gletscherschwankungen im Mont Blanc-Gebiet: Unteres Vallèe de Chamonix-Val Montjoie. Phys. Geographie, Vol. 22. Zürich.

ZOLLER, H. (1960 a): Pollenanalytische Untersuchungen zur Vegetationsgeschichte der insubrischen Schweiz. Denkschriften der Schweiz. Naturf. Ges., Bd. 83: 112 S.

ZOLLER, H. (1960 b): Die wärmezeitliche Verbreitung von Haselstrauch, Eichenmischwald, Fichte und Weißtanne in den Alpenländern. Bauhinia, 1/3: 189-207.

ZOLLER, H. (1963): Zur Chronologie der insubrischen Vegetationsgeschichte. Ber. Geobot. Inst. Rübel in Zürich, 34: 477-80.

ZOLLER, H. (1968): Geschichte der Paläobotanik und Palynologie in der Schweiz. Rev. Palaeobotan. Palynol., 7: 81-98.

ZOLLER, H. (1977): Alter und Ausmaß postglazialer Klimaschwankungen in den Schweizer Alpen. In: Dendrochronologie und postglaziale Klimaschwankungen in Europa, 13: 271-282.

ZOLLER, H., SCHINDLER, C. und RÖTHLISBERGER, $H$. (1966): Postglaziale Gletscherstände und Klimaschwankungen im Gotthardmassiv und Vorderrheingebiet. Verh. Naturf. Ges. in Basel, 77/2: 97-164.

ZOLLER, H. und KLEIBER, H. (1971 a): Vegetationsgeschichtliche Untersuchungen in der momentanen und subalpinen Stufe der Tessintäler. Verh. Naturf. Ges. in Basel, 81/1: 90-154.

ZOLLER, H. und KLEIBER, H. (1971 b): Überblick der spätund postglazialen Vegetationsgeschichte in der Schweiz. Boissiera, 19: 113-128.

ZUMBÜHL, H. J. (1980): Die Schwankungen der Grindelwaldgletscher in den historischen Bild- und Schriftquellen des 12.-19. Jahrhunderts. Denkschr. Schweiz. natf. Ges., Bd 92. Birkhäuser Basel/Boston/Stuttgart. 